Federal Reserve Bank of Minneapolis

Research Department

\title{
Buyers, Sellers and Middlemen: Variations in Search Theory*
}

\author{
Yuet-Yee Wong and Randall Wright \\ Working Paper 691
}

October 2011

\begin{abstract}
We study bilateral exchange, both direct trade and indirect trade that happens through chains of intermediaries or middlemen. We develop a model of this activity and present applications. This illustrates how, and how many, intermediaries get involved, and how the terms of trade are determined. Bargaining with intermediaries depends on how they bargain with downstream intermediaries, leading to interesting holdup problems. We discuss the roles of buyers and sellers in bilateral exchange, and how to interpret prices. We develop a particular bargaining solution and relate it to other solutions. We also illustrate how bubbles can emerge in the value of inventories.
\end{abstract}

JEL numbers: C78, D43, E40

Keywords: Middlemen; Search; Bargaining

*Wong: Department of Economics, Binghamton University; Randall Wright: Departments of Economics and Finance, University of Wisconsin-Madison, and Federal Reserve Bank of Minneapolis. We thank Todd Keister, Ken Burdett, Guido Menzio, Yiting Li, Andre Shevchenko, Abdulah Yavas, Adrian Masters, John Kennan, Fabian Postel-Vinay, Lonnes Smith, Abinay Muthoo, Bentley MacCleod, and Pierre Cahuc for input. Wright thanks the National Science Foundation and the Ray Zemon Chair in Liquid Assets in the Wisconsin School of Business. The views expressed herein are those of the authors and not necessarily those of the Federal Reserve Bank of Minneapolis or the Federal Reserve System. 
"You sell your own works directly, Mr Nelson?" Siobhan asked.

"Dealers have got the market sewn up," Nelson spat. "Bloodsucking bastards that they are ..." Resurrection Men (1991) by Ian Rankin

\section{Introduction}

We study bilateral exchange, both direct trade, and indirect trade that happens through intermediaries, or middlemen. We develop a model of this activity and present a sequence of applications. The framework illustrates how, and how many, middlemen get involved. Although there is much economic research on the topic, in general, a neglected aspect that seems important to business practitioners is that there are often multiple middlemen engaged in getting goods from the originator to end user - e.g., from farmer to broker to distributor to retailer to consumer. ${ }^{1}$ A feature we emphasize is that the terms of trade one might negotiate with an intermediary depend on upcoming negotiations with the second, third and other downstream intermediaries. We call this bargaining with bargainers. We also have something to say about the roles of buyers and sellers - in particular, which are which - in bilateral exchange, and about the interpretation of prices. We develop a particular bargaining solution and discuss how it relates to other solutions. Additionally, we illustrate how bubbles can emerge in the value of inventories as they get traded across intermediaries.

In terms of related work, it was not so long ago that Rubinstein and Wolinsky (1987) motivated their paper as follows:

Despite the important role played by intermediation in most markets, it is largely ignored by the standard theoretical literature. This is because a study of intermediation requires a basic model that describes explicitly the trade frictions that give rise to the function of intermediation. But this is missing from the standard market models, where the actual process of trading is left unmodeled.

\footnotetext{
${ }^{1}$ As a special case of this example, taken from Cooke (2000), consider illegal drugs. As another example, Ellis (2009) describes the internet like this: "If a majority of the wholesale companies being advertised are not true wholesale companies, then what are they and where are they getting their products? They are likely just middleman operating within a chain of middleman. A middleman chain occurs when a business purchases its resale products from one wholesale company, who in turn purchases the products from another wholesale company, which may also purchase the products from yet another wholesale company, and so on."
} 
Although we think there is more to be done, many subsequent studies have attempted to rectify the situation by analyzing the roles of middlemen, and how they affect the quality of matches, the time required to conduct transactions, the variety of goods on the market, bid-ask spreads, and other phenomena.

Rubinstein and Wolinsky (1987) themselves focus on search frictions, and for them, middlemen are agents who have an advantage over the original suppliers in the rate at which they meet buyers. Focusing instead on information frictions, Biglaiser (1993) and Li $(1998,1999)$ present models where middlemen are agents with expertise that allows them to distinguish high- from low-quality goods, and show how the presence of informed intermediaries helps to ameliorate lemons problems. In other papers (Camera 2001, Johri and Leach 2002, Shevchenko 2004, Smith 2004, Dong 2009, and Watanabe 2010a,b), middlemen hold inventories of either more, or more types of, commodities that help buyers obtain their preferred goods more easily. See also Kalai, Postlewaite and Roberts (1978), Bose and Sengupta (2010), Tse (2009), and Masters (2007,2008).

In general, middlemen may hold inventories or act as market makers that get buyers and sellers together (Yavas 1992,1994,1996; Gehrig 1993; Rust and Hall 2003). Models of these activities in financial markets include Duffie, Garleanu and Pedersen (2005), Miao (2006), Weill (2007), Lagos and Rocheteau (2009), and Lagos, Rocheteau and Weill (2009). Many of these applications can be considered part of the New Monetarist economics surveyed by Nosal and Rocheteau (2010) and Williamson and Wright (2010a,b), defined by an endeavor to explicitly model the exchange process, and institutions that facilitate this process, like money, intermediaries, etc., often using search theory. We say more later about the relationship between intermediation and money; for now, we mention that early search-based models of monetary exchange like Kiyotaki and Wright (1989) not only make predictions about which objects might emerge as media of exchange, as a function of their properties and agents' beliefs, they also make perhaps less-well-known predictions about which agents emerge as middlemen.

Search theory is the right tool for analyzing intermediaries, and related institutions, 
for the reason articulated by Rubinstein and Wolinsky: it models exchange explicitly. In a sense, this study is as much about search theory as it is about the substantive topic of middlemen. We set up the environment differently, in several ways, from previous studies. This is because we are less interested in why middlemen have a role, in the sense that much of the analysis revolves around environments where trade must be intermediated. Instead, we focus on equilibrium patterns of trade, with potentially long chains of intermediation, and the determination of the terms of trade. Still, for comparison, we present a version that generalizes standard models like Rubinstein and Wolinsky (1987). More ambitiously, we strive to bridge some gaps between disparate branches of search theory by showing how several ostensibly different models can be interpreted in light of our framework. This leads us to discuss several questions about models of bilateral trade, including, who is the buyer and who is the seller, and what is the price? In terms of price determination, we focus on a particular bargaining solution that we think is attractive for equilibrium search theory, but we also compare results for other more standard bargaining solutions.

A recently popular activity that our model captures is flipping, which according to Wikipedia involves "purchasing a revenue-generating asset and quickly reselling (or 'flipping') it for profit." Although one can flip any asset, the term is most often applied to real estate (and sometimes initial public offerings). In particular, as regards our focus on intermediation chains, "Under the multiple investor flip, one investor purchases a property at below-market value, assigns or sells it quickly to a second investor, who subsequently sells it to the final consumer, closer to market value." Of course, "Profits from flipping real estate come from either buying low and selling high (often in a rapidly-rising market), or buying a house that needs repair and fixing it up before reselling." We focus on the former, although it is easy to extend the model to the case where intermediaries add value. Moreover, as Wikipedia also emphasizes, it is common to think that this activity may have something to do with the generation of housing (and other) price bubbles, defined here as equilibria where the prices of inventories differ from their fundamental value. As we said above, our model is capable of generating bubble-like equilibria. 
The rest of the paper is organized as follows. Section 2 lays out some basic assumptions and examples. Section 3 presents our extension of standard models. Section 4 goes into detail concerning the dynamics of exchange and pricing in intermediated markets. Section 5 discusses bigger issues of interpretation in this class of models, including the relation between distinct branches of the search literature. Section 6 takes up bubbles. Section 7 concludes.

\section{The Model}

\subsection{Basic Assumptions}

Consider a set of agents $\mathcal{A}=\left\{A_{1}, A_{2}, \ldots A_{N}\right\}$, where $N \leq \infty$. They are spatially separated with the following connections: $A_{n}$ can meet, and hence trade, with $A_{n-1}$ and $A_{n+1}$ but no one else. We can represent the population as a graph with the set of nodes $\mathcal{A}$ connected as show in Figure 1. There are search frictions, which means it can take time and other resources for $A_{n}$ to meet $A_{n+1}$. There is an indivisible object $x$ in fixed supply, and a divisible object $y$ that anyone can produce at unit cost (i.e., the utility of producing $y$ units of this object is $-y$ ). Only $A_{1}$ is endowed with $x$, and he can either try to trade it to $A_{2}$ in exchange for $y_{1}$, or consume it himself for utility $\gamma_{1}$. Hence, $\gamma_{1}$ is $A_{1}$ 's opportunity cost of trading $x$, although for many purposes one can alternatively interpret it as a production cost.

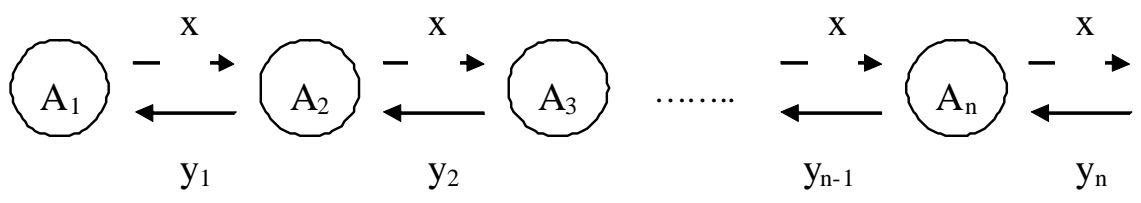

Figure 1: Population graph

More generally, if any agent $A_{n}$ acquires $x$ from $A_{n-1}$, he can either consume it for payoff $\gamma_{n}$, or try to trade it to $A_{n+1}$ for payoff $u\left(y_{n}\right)=y_{n}$. If $A_{1}$ trades $x$ to $A_{2}$ and $A_{2}$ trades it to $A_{3} \ldots$ before some $A_{N}$ eventually consumes it, we say trade is intermediated and call $A_{2}, \ldots A_{N-1}$ intermediaries or middlemen (in principle $A_{n}$ could also try to trade $x$ back to $A_{n-1}$ but this never happens). For most of what we do it is assumed that $A_{n}$ exits the 
market after trading $x$ to $A_{n+1} .^{2}$

\subsection{Example: $N=2$}

Consider an economy with $N=2$ - or, equivalently, for this exercise, $N=\infty$ with $\gamma_{n}>0$ for $n \leq 2$ and $\gamma_{n}=0$ for all $n>2$, since this implies $x$ will never be traded beyond $A_{2}$ (see below). In this case there can be no middlemen, but it is still useful as a vehicle to illustrate our trading protocol and as an input into the more interesting cases to follow. We begin by ignoring search, and asking what happens if $A_{1}$ happens to meet $A_{2}$. If $\gamma_{2} \leq \gamma_{1}$, there are no gains from trade, and $A_{1}$ consumes $x$. If $\gamma_{2}>\gamma_{1}$, they play the following game:

Stage 1: $A_{1}$ moves by making an offer "give me $y_{1}$ for $x . "$

Stage 2: $A_{2}$ moves by accepting or rejecting, where:

- accept means the game ends;

- reject means we go to stage 3 .

Stage 3: Nature moves (a coin toss) with the property that:

- with probability $\theta_{1}, A_{1}$ makes $A_{2}$ a take-it-or-leave-it offer;

- with probability $1-\theta_{1}, A_{2}$ makes $A_{1}$ a take-it-or-leave-it offer.

Figure 2 shows the game tree. ${ }^{3}$ If the initial offer $y_{1}$ is accepted, $A_{1}$ gets payoff $y_{1}$ and $A_{2}$ gets $\gamma_{2}-y_{1}$. If $y_{1}$ is rejected, with probability $\theta_{1}, A_{1}$ gets the whole surplus leaving $A_{2}$

\footnotetext{
${ }^{2}$ If one wants to keep the economy going forever, it is simple to replace every $A_{n}$ with a "clone" of himself after he leaves the market (see e.g. Burdett and Coles 1997). As an alternative to "cloning" in Section 3 we "recycle" agents by allowing them to continue rather than exit after trade.

${ }^{3}$ We are not sure of the original use of this extensive form, but it is obviously related to Stahl (1972), Rubinstein (1982), Binmore (1987) and McCleod and Malcomson (1993), to name a few. The exact specification, with just two rounds of bargaining where the second has a coin toss to determine who makes the final offer, appeared in early versions of Cahuc, Postel-Vinay and Robin (2006), but they ultimately switched to a more standard game, which gives the same results in their moddel. We say more about this below. For now, we mention that it is more interesting with nonlinear utility, since with linearity one can actually ignore the first round and just use a coin toss to determine who makes a take-it-or-leave-it offer (as in several previous search models, e.g., Gale 1990 or Mortensen and Wright 2002). Since a coin toss induces risk, however, with nonlinear utility that mechanism is not bilaterally efficient.
} 


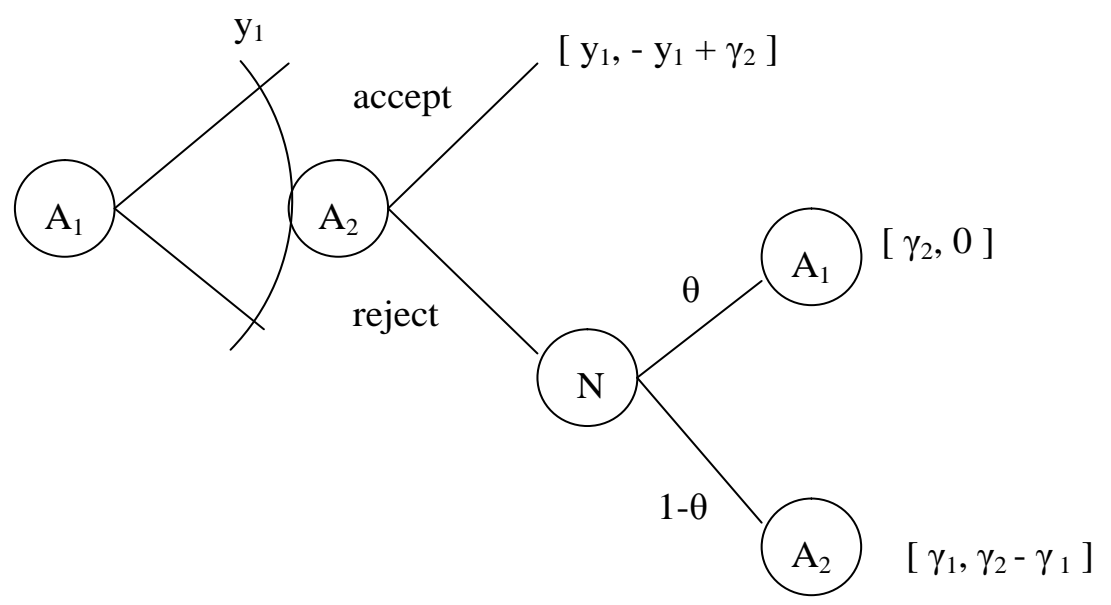

Figure 2: Game tree

with his outside option 0 , and with probability $1-\theta_{1}, A_{1}$ gets his outside option $\gamma_{1}$ while $A_{2}$ gets the surplus $\gamma_{2}-\gamma_{1}$. The unique subgame perfect equilibrium is: at stage $1, A_{1}$ makes $A_{2}$ his reservation offer, which means $A_{2}$ indifferent between accepting and rejecting, and he accepts. ${ }^{4}$ The indifference condition is $\gamma_{2}-y_{1}=\left(1-\theta_{1}\right)\left(\gamma_{2}-\gamma_{1}\right)$, or

$$
y_{1}=\left(1-\theta_{1}\right) \gamma_{1}+\theta_{1} \gamma_{2} .
$$

Payoffs are $V_{1}=\gamma_{1}+\theta_{1}\left(\gamma_{2}-\gamma_{1}\right)$ and $V_{2}=\left(1-\theta_{1}\right)\left(\gamma_{2}-\gamma_{1}\right)$. Of course, agents are not compelled to participate, but as long as $\gamma_{2}>\gamma_{1}$ we have $V_{1} \geq \gamma_{1}$ and $V_{2} \geq 0$, so the payoffs beat the outside options. Equivalently, defining the total surplus as the sum of payoffs minus outside options, $S_{12}=V_{1}-\gamma_{1}+V_{2}=\gamma_{2}-\gamma_{1}$, the agents trade as long as $S_{12} \geq 0$.

For comparison, consider the standard generalization of Nash (1950) bargaining, where threat points are given by the outside options:

$$
y_{1}=\arg \max _{y}\left(y-\gamma_{1}\right)^{\theta_{1}}\left(\gamma_{2}-y\right)^{1-\theta_{1}}
$$

It is easy to see that this is equivalent to (1). Hence, our game implements the Nash solution. It also implements Kalai's (1977) proportional bargaining solution, which has

\footnotetext{
${ }^{4}$ This is almost but not quite right. If agents are risk neutral there is an equilibrium where the initial offer is rejected and we move to Stage 2, but it is payoff equivalent. One can refine that away by assuming a small probability of an exogenous breakdown, or discounting, between rounds. Or, as we do below, one can assume risk aversion. In either case the outcome in the text is the unique equilibrium.
} 
become popular in search theory recently (see Lester, Postlewaite and Wright 2010, e.g., for an application and references), since it is the same as Nash in this example, giving $A_{1}$ a fraction $\theta_{1}$ of $S_{12}$. We call the probability $\theta_{n}$ the bargaining power of $A_{n}$ when he plays with $A_{n+1}$, and allow it to vary across agents, because we believe it is an important component of intermediation - e.g., one reason that athletes, artists, etc. employ agents may have to do with comparative advantage in bargaining. ${ }^{5}$

If it takes time and effort for $A_{n}$ to meet $A_{n+1}$, the value of search is

$$
r \bar{V}_{n}=\alpha_{n}\left(y_{n}-\bar{V}_{n}\right)-c_{n}
$$

where $r$ is the rate of time preference, $\alpha_{n}$ a Poisson arrival rate, $c_{n}$ a flow search cost, and we distinguish $\bar{V}_{n}$, the value of looking for a game, from $V_{n}$, the value of playing one. Since $c_{n}$ is only paid when $A_{n}$ has $x$ and is looking for $A_{n+1}$, not when $A_{n-1}$ is looking for $A_{n}$, we can also interpret it as an inventory carrying or storage cost. In any case, we have

$$
\bar{V}_{n}=\frac{\alpha_{n} y_{n}-c_{n}}{r+\alpha_{n}}
$$

and $A_{n}$ is willing to search for $A_{n+1}$ only if this exceeds his opportunity cost $\gamma_{n}$, or

$$
\left(r+\alpha_{n}\right) \gamma_{n} \leq \alpha_{n} y_{n}-c_{n}
$$

Using (4) and (1), we see that search by $A_{1}$ is viable iff

$$
c_{1}+\left(r+\alpha_{1}\right) \gamma_{1} \leq \alpha_{1}\left[\left(1-\theta_{1}\right) \gamma_{1}+\theta_{1} \gamma_{2}\right]
$$

which says the expected payoff covers the direct search cost and opportunity cost, appropriately capitalized. Since (5) implies $S_{12} \geq 0$, the binding constraint for trade is the viability of search, not the outside options. We can let the search frictions vanish either by letting $r \rightarrow 0$ and $c_{1} \rightarrow 0$, or letting $\alpha_{n} \rightarrow \infty$, since all that matters is $r / \alpha_{n}$ and $c_{n} / \alpha_{n}$. When the search frictions vanish, (5) holds, which means search is viable, iff $S_{12} \geq 0$.

\footnotetext{
${ }^{5}$ Rubinstein and Wolinsky (1987) use a simple surplus-splitting rule, corresponding to $\theta_{n}=1 / 2$ in our game when we have linear utility (but see below, where we have nonlinear utility). They say "The reason that we abandon the strategic approach [used in their 1985 paper] here is that it would greatly complicate the exposition without adding insights." Binmore, Rubinstein and Wolinsky (1986) provide a strong argument in favor of the strategic approach - it makes the timing, threat points, etc. less ambiguous - and we find this clarifies rather than "greatly complicating" the analysis. Also, whatever approach one takes, it is clearly desirable to go beyond the symmetric case $\theta=1 / 2$ (see also Masters 2007,2008).
} 


\subsection{Example: $N=3$}

Now consider $N=3$ : an originator $A_{1}$; a potential end user $A_{3}$; and a potential middleman $A_{2}$ (or, equivalently, for this exercise, $N=\infty$ with $\gamma_{n}=0$ for all $n>3$ ). Note that $A_{3}$ is an end user in the sense that if he acquires $x$ he consumes it, since there is no one left to take it off his hands, but it is possible that $A_{1}$ prefers consuming $x$ rather than searching for $A_{2}$, or $A_{2}$ prefers consuming it rather than searching for $A_{3}$. Different from some related models, here $A_{1}$ and $A_{3}$ cannot meet directly (this is relaxed in Section 3). Hence, the only way to get $x$ from $A_{1}$ to $A_{3}$ is via the intermediary $A_{2} \cdot{ }^{6}$

Given these assumptions, we ask which trades occur, and at what terms. Working backwards, if $A_{2}$ with $x$ meets $A_{3}$ then, as in the case $N=2$, we have

$$
y_{2}=\left(1-\theta_{2}\right) \gamma_{2}+\theta_{2} \gamma_{3}
$$

Payoffs from this trade are $V_{2}=y_{2}$ and $V_{3}=\left(1-\theta_{2}\right)\left(\gamma_{3}-\gamma_{2}\right)$, and the total surplus is $S_{23}=\gamma_{3}-\gamma_{2}$, so they trade as long as $\gamma_{3} \geq \gamma_{2}$. More stringently, for search by $A_{2}$ to be viable we require $\bar{V}_{2} \geq \gamma_{2}$, or

$$
c_{2}+\left(r+\alpha_{2}\right) \gamma_{2} \leq \alpha_{2}\left[\left(1-\theta_{2}\right) \gamma_{2}+\theta_{2} \gamma_{3}\right] .
$$

If (7) holds then, upon acquiring $x, A_{2}$ looks to trade it to $A_{3}$; if (7) fails then $A_{2}$ consumes $x$ himself. In the latter case, $A_{3}$ is irrelevant, and effectively we have $N=2$.

So, suppose (7) holds, and back up to where $A_{1}$ meets $A_{2}$. When $A_{1}$ makes the initial offer $y_{1}, A_{2}$ 's indifference condition is $-y_{1}+\bar{V}_{2}=\left(1-\theta_{1}\right)\left(\bar{V}_{2}-\gamma_{1}\right)$. Inserting $\bar{V}_{2}$, we have

$$
y_{1}=\left(1-\theta_{1}\right) \gamma_{1}+\theta_{1} \frac{\alpha_{2} y_{2}-c_{2}}{r+\alpha_{2}} .
$$

The payoffs are $V_{1}=y_{1}$ and $V_{2}=\left(1-\theta_{1}\right)\left(\frac{\alpha_{2} y_{2}-c_{2}}{r+\alpha_{2}}-\gamma_{1}\right)$, and $S_{12} \geq 0$ iff

$$
c_{2} \leq-\gamma_{1}\left(r+\alpha_{2}\right)+\alpha_{2}\left[\theta_{2} \gamma_{3}+\left(1-\theta_{2}\right) \gamma_{2}\right] .
$$

\footnotetext{
${ }^{6}$ Thus, we cannot ask here why the market doesn't cut out the middlemen - or, in more modern jargon, why there isn't disintermediation. On that issue, practioners say this: "why doesn't every wholesaler just buy from the manufacture and get the deepest discount? The answer is simple - not all wholesalers (or companies claiming to be wholesalers) can afford to purchase the minimum bulk-order requirements that a manufacture requires. Secondly, many manufactures only do business with companies that are established" (Ellis 2009). We do not model this explicitly, but it might be worth pursuing in future work.
} 
More stringently, for search by $A_{1}$ to be viable we require $\bar{V}_{1} \geq \gamma_{1}$, or using (6) and (8)

$$
c_{1} \leq-\left(r+\alpha_{1}\right) \gamma_{1}+\alpha_{1}\left\{\left(1-\theta_{1}\right) \gamma_{1}+\theta_{1} \frac{\alpha_{2}\left[\left(1-\theta_{2}\right) \gamma_{2}+\theta_{2} \gamma_{3}\right]-c_{2}}{r+\alpha_{2}}\right\} \text {. }
$$

Summarizing, after some algebra, for $x$ to pass from $A_{1}$ to $A_{2}$ to $A_{3}$ we require

$$
\begin{aligned}
\left(r+\alpha_{2}\right) c_{1}+\alpha_{1} \theta_{1} c_{2} & \leq-\left(r+\alpha_{1} \theta_{1}\right)\left(r+\alpha_{2}\right) \gamma_{1}+\alpha_{1} \theta_{1} \alpha_{2}\left(1-\theta_{2}\right) \gamma_{2}+\alpha_{1} \theta_{1} \alpha_{2} \theta_{2} \gamma_{3} \\
c_{2} & \leq-\left(r+\alpha_{2} \theta_{2}\right) \gamma_{2}+\alpha_{2} \theta_{2} \gamma_{3}
\end{aligned}
$$

If the inequality in (10) is reversed then $A_{2}$ consumes $x$ if he gets it, and he gets it if

$$
c_{1} \leq-\left(r+\alpha_{1} \theta_{1}\right) \gamma_{1}+\alpha_{1} \theta_{1} \gamma_{2}
$$

since this makes search by $A_{1}$ viable when $A_{2}$ consumes $x$. Note that reversing the inequality in (11) means $A_{1}$ will not search for $A_{2}$ given $A_{2}$ consumes $x$, but search by $A_{1}$ may still be viable if $A_{2}$, instead of consuming $x$, flips it to $A_{3}$. As a special case, when search frictions vanish $\left(r \rightarrow 0\right.$ and $\left.c_{n} \rightarrow 0\right)$, search by $A_{2}$ is viable iff $\gamma_{3} \geq \gamma_{2}$. Given $A_{2}$ searches, in this case, search by $A_{1}$ is viable iff $\gamma_{1} \leq\left(1-\theta_{2}\right) \gamma_{2}+\theta_{2} \gamma_{3}$. Alternatively, if $A_{2}$ does not search because $\gamma_{3}<\gamma_{2}$, then search by $A_{1}$ is viable iff $\gamma_{2} \geq \gamma_{1}$.

To develop some more economic intuition, return to the case there are search frictions, $r>0$ and $c_{n}>0$, but now suppose $\gamma_{2}=0$ so that $A_{2}$ is a pure middleman, with no desire to consume $x$ himself. If $A_{2}$ obtains $x$ he searches for $A_{3}$ if the expected payoff exceeds the pure search cost, $\alpha_{2} \theta_{2} \gamma_{3} \geq c_{2}$. If this inequality is reversed $A_{2}$ does not want $x$, and the market shuts down. But if $\alpha_{2} \theta_{2} \gamma_{3} \geq c_{2}$, so that $A_{2}$ would search for $A_{3}$, then $A_{1}$ searches for $A_{2}$ iff

$$
\left(r+\alpha_{2}\right) c_{1}+\alpha_{1} \theta_{1} c_{2} \leq-\left(r+\alpha_{1} \theta_{1}\right)\left(r+\alpha_{2}\right) \gamma_{1}+\alpha_{1} \theta_{1} \alpha_{2} \theta_{2} \gamma_{3}
$$

In words, the RHS is $A_{1}$ 's expected share of $A_{2}$ 's expected share of the end user's payoff, net of his opportunity cost, while the LHS is $A_{1}$ 's direct search cost and the amount he has to compensate $A_{2}$ for $A_{2}$ 's search costs, all appropriately capitalized.

When $\gamma_{2}=0$, and additionally $r \rightarrow 0$ and $c_{n} \rightarrow 0, A_{1}$ searches for $A_{2}$ who searches for $A_{3}$ iff $\theta_{2} \gamma_{3} \geq \gamma_{1}$. The salient point is that $\gamma_{3}>\gamma_{1}$ is not enough to get $x$ from $A_{1}$ to $A_{3}$, 
even when $\gamma_{2}, r$ and $c_{n}$ are negligible. This is a typical holdup problem. Potential middleman $A_{2}$ knows that $A_{3}$ is willing to give anything up to $\gamma_{3}$ to get $x$, and $A_{1}$ would be willing to let it go for as little as $\gamma_{1}$, which sounds like there is a deal to be done. But when $A_{2}$ meets $A_{3}$ he only gets $y_{2}=\theta_{2} \gamma_{3}$. He may protest he needs more just to cover his cost, in this case $y_{1}=\left(1-\theta_{1}\right) \gamma_{1}+\theta_{1} \theta_{2} \gamma_{3}$. Being educated in economics, however, $A_{3}$ would (implicitly) counter that this cost is sunk and irrelevant for the negotiations. And he would be right. Hence $A_{2}$ will not intermediate a deal unless $y_{2} \geq y_{1}$, or $\theta_{2} \gamma_{3} \geq \gamma_{1}$ in this case. This market failure is due to lack of commitment. If $A_{3}$ and $A_{2}$ could sign a binding ex ante contract, the former could commit to paying the latter at least enough to cover his cost, but such commitment is proscribed here - as in many search models, it seems reasonable to assume you cannot contract with someone before you contact someone.

Without the assumptions $r \rightarrow 0, c_{n} \rightarrow 0$ and $\gamma_{2}=0$, the results are similar, but richer e.g., there is an additional aspect of holdup as the cost $c_{2}$ is also sunk when $A_{2}$ meets $A_{3}$. Note the asymmetry: $A_{3}$ does not compensate $A_{2}$ for his search cost, but $A_{1}$ does compensate $A_{2}$ for his, because only in the former negotiations is the costs sunk; similarly, $A_{1}$ shares in the upstream value $\gamma_{3}$ but $A_{3}$ does not share in the downstream cost $y_{1}$. A general conclusion to draw from this is that whether trade even gets off the ground, as well as the terms of trade and payoffs when it does, depend on not only fundamentals and bargaining power in any bilateral trading opportunity, but also on these parameters in downstream opportunities. In particular, gains from trade between $A_{1}$ and $A_{2}$ depend on $A_{2}$ 's bargaining power when he later meets $A_{3}$. This is what we call bargaining with bargainers. ${ }^{7}$

\section{Competing Risks}

Here we present a formulation where, as in many of the models discussed in the Introduction, there are large numbers of agents of each type, and any agent can meet any other. Following most of the literature, there are $N=3$ types: originators $A_{1}$, potential middlemen $A_{2}$, and

\footnotetext{
${ }^{7}$ To close this section, note that our game again implements the generalized Nash or proportional bargaining outcome, where the surplus for $A_{n}$ is $y-\gamma_{n}$, and the surplus for $A_{n+1}$ it is $\bar{V}_{n+1}-y$ if he searches and $\gamma_{n+1}-y$ otherwise.
} 
potential end users $A_{3}$, with $\gamma_{1}=\gamma_{2}=0<\gamma_{3}$. As in competing risk models in duration analysis, from whence we take the name, there is e.g. a risk of $A_{1}$ meeting either $A_{2}$ or $A_{3}$. Also, agents here continue in, rather than exit from, the market after trade.

With more types of meetings we need more notation. Let $\sigma_{n} \in\{0,1\}$ indicate whether $A_{n}$ searches, $n=1,2$; let $\mu \in\{0,1\}=1$ indicate whether $A_{1}$ trades with $A_{2}$; and let $m$ be the steady state probability that $A_{2}$ is in possession of $x$. To keep track of $A_{2}$ 's inventory, write $\bar{V}_{2 i}$ where $i \in\{0,1\}$. Also, let $\alpha_{n n^{\prime}}$ be the rate at which $A_{n}$ meets $A_{n^{\prime}}$, and $y_{n n^{\prime}}$ the equilibrium outcome in their bargaining game. The value functions satisfy: ${ }^{8}$

$$
\begin{aligned}
r \bar{V}_{1} & =\alpha_{12}(1-m) \mu y_{12}+\alpha_{13} y_{13}-c_{1} \\
r \bar{V}_{3} & =\sigma_{1} \alpha_{31}\left(\gamma_{3}-y_{13}\right)+\sigma_{2} \alpha_{32} m\left(\gamma_{3}-y_{23}\right) \\
r \bar{V}_{20} & =\sigma_{1} \alpha_{21} \mu\left(\bar{V}_{21}-\bar{V}_{20}-y_{12}\right) \\
r \bar{V}_{21} & =\alpha_{23}\left(y_{23}+\bar{V}_{20}-\bar{V}_{21}\right)-c_{2}
\end{aligned}
$$

The indifference conditions in bargaining are:

$$
\begin{aligned}
\gamma_{3}-y_{13} & =\left(1-\theta_{13}\right) \gamma_{3} \\
\gamma_{3}-y_{23} & =\left(1-\theta_{23}\right)\left(\gamma_{3}+\bar{V}_{20}-\bar{V}_{21}\right) \\
\bar{V}_{21}-\bar{V}_{20}-y_{12} & =\left(1-\theta_{12}\right)\left(\bar{V}_{21}-\bar{V}_{20}\right)
\end{aligned}
$$

Let the population be given by $\left(\pi_{1}, \pi_{2}, \pi_{3}\right)$, where $\pi_{n}$ is the measure of type $A_{n}$ agents, with $\pi_{1}+\pi_{2}+\pi_{3}=1$. Since the number of meetings between $n$ and $n^{\prime}$ must be the same as the number of meetings between $n^{\prime}$ and $n$, we have three identities: $\pi_{1} \alpha_{12}=\pi_{2} \alpha_{21}$, $\pi_{2} \alpha_{23}=\pi_{3} \alpha_{32}$, and $\pi_{3} \alpha_{31}=\pi_{1} \alpha_{13}$. The steady state value of $m$ is given by the equating the inflow and outflow of $A_{2}$ inventories, $m \alpha_{23}=(1-m) \alpha_{21} \mu$, which solves for

$$
m=\frac{\pi_{1} \alpha_{12} \mu}{\pi_{2} \alpha_{23}+\pi_{1} \alpha_{12} \mu} .
$$

\footnotetext{
${ }^{8}$ These equations give the value of searching, but since $A_{n}$ has the option of not searching, for $n=1,2$, free disposal implies the value of $x$ is $\max \left\{0, \bar{V}_{n}\right\}$. Also, due to "recycling" there is no capital gain term when $A_{1}$ or $A_{3}$ trade - e.g., the surplus for $A_{1}$ from trading with $A_{2}$ is $y_{12}$ plus continuation value $\bar{V}_{1}$, minus the outside option $\bar{V}_{1}$, which nets to $y_{12}$.
} 
A steady state equilibrium is described by the trade decision $\mu$ between $A_{1}$ and $A_{3}$ and search decisions $\sigma_{1}$ and $\sigma_{2}$ satisfying conditions discussed below, along with terms of trade, value functions and inventory distribution solving (12)-(19).

Depending on parameters, different types of equilibria can arise. In type 0 equilibrium, $A_{1}$ does not search and the market shuts down; in type 1 equilibrium, $A_{1}$ searches and trades $x$ to $A_{3}$ but not $A_{2}$, so that middleman are inactive; and in type 2 equilibrium, $A_{1}$ searches and trades $x$ to $A_{3}$ or $A_{2}$, and $A_{2}$ searches for $A_{3}$, so there is intermediated trade. These are the only possible outcomes. ${ }^{9}$ However, even if $A_{1}$ does not search (i.e., $\sigma_{1}=0$ ), we must specify as part of the equilibrium whether $A_{1}$ and $A_{2}$ would trade, if they were to meet, off the equilibrium path (subgame perfection). To construct the equilibrium set, ergo, we must check the following. First are the search decisions: $\sigma_{1}=1$ if $\bar{V}_{1}>0$ and $\sigma_{1}=0$ if $\bar{V}_{1}<0$; $\sigma_{2}=1$ if $\bar{V}_{21}>\bar{V}_{20}$ and $\sigma_{2}=0$ if $\bar{V}_{21}<\bar{V}_{20}$. Then there is the condition that determines whether $A_{1}$ and $A_{2}$ trade: $\mu=1$ if $S_{12}>0$ and $\mu=0$ if $S_{12}<0$, where $S_{12}=\bar{V}_{21}-\bar{V}_{20}$. Note $\sigma_{2}=1$ iff $\mu=1$. Hence, in what follows, we focus on trading decisions.

Here we emphasize the economics, relegating algebra to Appendix A. We begin with type 0 equilibrium, where $A_{1}$ does not search. There are two versions of this equilibrium: one where $A_{1}$ and $A_{2}$ would trade if were to meet; one where they would not. For the latter, to guarantee $\mu=0$ we need $\alpha_{23} \theta_{23} \gamma_{3} \leq c_{2}$, and to guarantee $\sigma_{1}=0$ we need $\alpha_{13} \theta_{13} \gamma_{3} \leq c_{1}$, shown in the upper right of Figure 3 . For the former, where $A_{1}$ does not search but if would trade with $A_{2}$ were they to meet, we need $\alpha_{23} \theta_{23} \gamma_{3} \geq c_{2}$ to guarantee $\mu=1$ and

$$
\begin{aligned}
0 \geq & \left(\pi_{2} \alpha_{23}+\pi_{1} \alpha_{12}\right)\left[\pi_{2} r+\pi_{2} \alpha_{23} \theta_{23}+\pi_{1} \alpha_{12}\left(1-\theta_{12}\right)\right]\left(\alpha_{13} \theta_{13} \gamma_{3}-c_{1}\right) \\
& +\alpha_{12} \alpha_{23} \pi_{2}^{2} \theta_{12}\left(\alpha_{23} \theta_{23} \gamma_{3}-c_{2}\right)
\end{aligned}
$$

to guarantee $\sigma_{1}=0$, also shown in Figure 3. When transactions costs are above certain thresholds, trade shuts down, which is no surprise; the point of the analysis is to determine exactly how the thresholds depend on the search and bargaining parameters, given by the $\alpha$ 's and $\theta$ 's, as well as the fundamental value of $x$, given by $\gamma_{3}$.

\footnotetext{
${ }^{9}$ One can check that if $A_{1}$ or $A_{2}$ with $x$ meets $A_{3}$ they always trade, which limits the number of types of equilibria.
} 


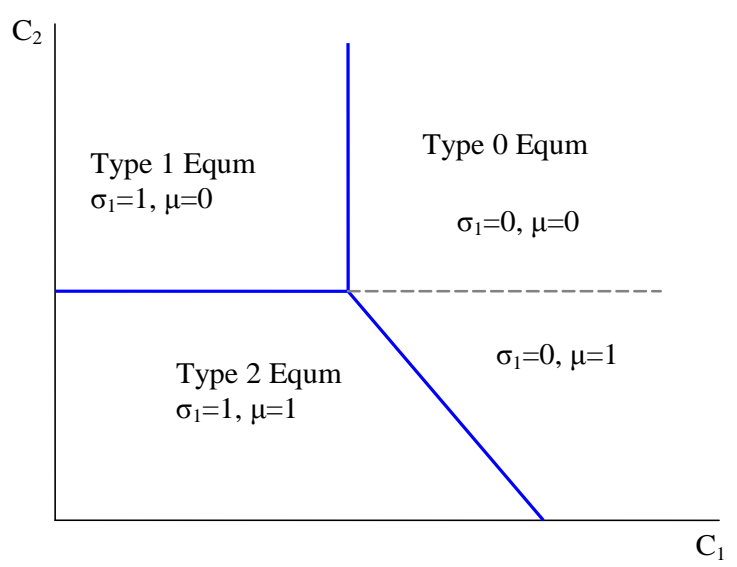

Figure 3: Equilibria in competing risk model

In terms of equilibria where the market does not shut down, type 1 equilibrium with $\sigma_{1}=1$ and $\mu=0$ exists iff $\alpha_{13} \theta_{13} \gamma_{3} \geq c_{1}$ and $\alpha_{23} \theta_{23} \gamma_{3} \leq c_{2}$, also shown in Figure 3. In this equilibrium $A_{1}$ searches but does not trade with $A_{2}$, either because $A_{2}$ has high search $\operatorname{costs}\left(c_{2} / \gamma_{3}\right.$ is big), meets $A_{3}$ infrequently ( $\alpha_{23}$ is small), or bargains poorly $\left(\theta_{23}\right.$ is low $)$. By contrast, in type 2 equilibrium, where $\sigma_{1}=1$ and $\mu=1$, middlemen do play a role. This equilibrium exists iff $\alpha_{23} \theta_{23} \gamma_{3} \geq c_{2}$ and

$$
\begin{aligned}
0 \leq & \left(\pi_{2} \alpha_{23}+\pi_{1} \alpha_{12}\right)\left[\pi_{2} r+\pi_{2} \alpha_{23} \theta_{23}+\pi_{1} \alpha_{12}\left(1-\theta_{12}\right)\right]\left(\alpha_{13} \theta_{13} \gamma_{3}-c_{1}\right) \\
& +\alpha_{12} \alpha_{23} \pi_{2}^{2} \theta_{12}\left(\alpha_{23} \theta_{23} \gamma_{3}-c_{2}\right)
\end{aligned}
$$

again shown in Figure 3. The diagonal line represents how $A_{1}$ 's search decision depends on $c_{2}$, because $y_{12}$ depends on $A_{2}$ 's expected cost and benefit from search.

In type 2 equilibrium, with active middlemen, one can check their profit margin is

$$
y_{23}-y_{12} \propto \theta_{23}\left(\gamma_{3} r+c_{2}\right)+\left(1-\theta_{12}\right)\left[\theta_{23} \gamma_{3}\left(\alpha_{23}+\alpha_{21}\right)-c_{2}\right]>0 .
$$

This is increasing in $\alpha_{23}$, the rate at which $A_{2}$ trades with $A_{3} \cdot{ }^{10}$ Note that in the limit as

\footnotetext{
${ }^{10}$ This follows from calculating

$$
y_{23}=\frac{\left[r+\alpha_{23}+\sigma_{1} \alpha_{21} \mu\left(1-\theta_{12}\right)\right] \theta_{23} \gamma_{3}-\left(1-\theta_{23}\right) c_{2}}{r+\theta_{23} \alpha_{23}+\sigma_{1} \alpha_{21} \mu\left(1-\theta_{12}\right)} \text { and } y_{12}=\frac{\theta_{12}\left(\alpha_{23} \theta_{23} \gamma_{3}-c_{2}\right)}{r+\theta_{23} \alpha_{23}+\sigma_{1} \alpha_{21} \mu\left(1-\theta_{12}\right)},
$$

and noting that the second term on the LHS of (22) is positive by the equilibrium condition for $\mu=1$. Unlike Rubinstein and Wolinsky (1987), we cannot show $y_{23}>y_{13}>y_{12}$, in general, although we can in the symmetric case $\theta_{n n^{\prime}}=1 / 2$.
} 
$r \rightarrow 0$ the market shuts down. The reason is that when either $A_{1}$ or $A_{2}$ trade with $A_{3}$, if $r \approx 0$ they only get their outside option, which is not enough for search to be viable in the first place - again, a holdup problem. In Rubinstein and Wolinsky (1987), by contrast, the profit margin vanishes as $r \rightarrow 0$, but the market still operates.

Intuitively, for intermediaries to have an active role $A_{2}$ must have a comparative advantage over $A_{1}$ in terms of costs, arrival rates or bargaining power (generalizing the standard model that considers only differences in arrival rates). The most interesting case is when $\left(c_{1}, c_{2}\right)$ is below the diagonal line in Figure 3, where we have equilibrium with active intermediaries, while if intermediation were not available, or most costly, the market would shut down completely. Note, however, that these substantive results are not very different from what we find in our baseline model, where $A_{n}$ can only trade $x$ to $A_{n+1}$. Indeed, a diagram similar to Fig 3 can be drawn for that model, partitioning $\left(c_{1}, c_{2}\right)$ space into four regions with similar economic properties - the main difference being that, in the baseline model, when $A_{2}$ does not search it means he consumes $x$, while in this version it means he disposes of it, and hence he never accepts it in the first place. In any case, having solved this model, we now return to the baseline specification to investigate longer intermediation chains.

\section{Multiple Middlemen}

When $A_{n+1}$ receives offer $y_{n}$ from $A_{n}$, given that he plans to trade $x$ again, his indifference condition is

$$
\frac{\alpha_{n+1} y_{n+1}-c_{n+1}}{r+\alpha_{n+1}}-y_{n}=\left(1-\theta_{n}\right)\left(-\gamma_{n}+\frac{\alpha_{n+1} y_{n+1}-c_{n+1}}{r+\alpha_{n+1}} .\right)
$$

Solving for $y_{n}$, we have

$$
y_{n}=\left(1-\theta_{n}\right) \gamma_{n}+\theta_{n} \frac{\alpha_{n+1} y_{n+1}-c_{n+1}}{r+\alpha_{n+1}} \equiv \rho_{n}\left(y_{n+1}\right)
$$

We interpret $y_{n}=\rho_{n}\left(y_{n+1}\right)$ as something like a best response condition for $A_{n}$ : it gives $y_{n}$, his initial offer strategy when he meets $A_{n+1}$, as a function of others' strategies, as summarized by $y_{n+1}$, since that is all he needs to know to choose $y_{n}$. 
Conditional on $A_{n}$ having acquired $x$, it is easy to see that $A_{n}$ and $A_{n+1}$ end up trading in equilibrium iff:

1. $\bar{V}_{n}=\frac{\alpha_{n} y_{n}-c_{n}}{r+\alpha_{n}} \geq \gamma_{n}$, so $A_{n}$ wants to search;

2. $V_{n, n+1}=y_{n} \geq \gamma_{n}$, so $A_{n}$ wants to trade;

3. $V_{n+1, n}=-y_{n}+\bar{V}_{n+1} \geq 0$, so $A_{n+1}$ wants to trade.

The second condition is not binding given the first, while the third reduces to ${ }^{11}$

$$
y_{n+1} \geq \frac{\gamma_{n}\left(r+\alpha_{n+1}\right)+c_{n+1}}{\alpha_{n+1}}
$$

Now, to investigate how long intermediation chains can be, consider a quasi-stationary environment, where $\alpha_{n}, c_{n}$ and $\theta_{n}$ are the same for all $n$, while $\gamma_{n}=\gamma$ for $n \leq N, \gamma_{N+1}=\hat{\gamma}>\gamma$, and $\gamma_{n}=0$ for $n>N+1$. We call $A_{N+1}$ the end user because, if he gets $x$, he consumes it, since $A_{n}$ does not value $x$ for $n>N+1 .^{12}$

Now $(24)$ can be written $y_{n}=\rho\left(y_{n+1}\right)$ for $n<N$, where $\rho(y)=(1-\theta) \gamma+\theta(\alpha y-c) /(r+\alpha)$, while $y_{N}=(1-\theta) \gamma+\theta \hat{\gamma}$. Clearly, $\rho(y)$ has a unique fixed point,

$$
y^{*}=\frac{(1-\theta) \gamma(r+\alpha)-\theta c}{r+\alpha(1-\theta)},
$$

where we assume $c<(1-\theta) \gamma(r+\alpha) / \theta$ so $y^{*}>0$. It is easy to see $y_{N}>\gamma>y^{*}>\rho(0)$, as in Figure 4. The way to read in Figure 4 is: given $A_{n+1}$ correctly anticipates getting $y_{n+1}$ from $A_{n+2}$, in bargaining with $A_{n}$ the equilibrium outcome is $y_{n}$. Now, to find equilibrium, begin by working backwards: set $y_{N}=(1-\theta) \gamma+\theta \hat{\gamma}$ and iterate on $y_{n}=\rho\left(y_{n+1}\right)$ to construct a sequence $\left\{y_{n}\right\}$, where it is obvious that $y_{n} \rightarrow y^{*}$ as $n \rightarrow-\infty$. Then, since we are actually interested in what happens as $n$ increases, moving forward in real time, pick a point in this sequence and iterate forward. This generates a candidate equilibrium.

The sequence $\left\{y_{n}\right\}$ is only a candidate equilibrium because we still have to check if search is viable for all agents in the chain. Clearly we cannot have arbitrarily long chains, since,

\footnotetext{
${ }^{11}$ By inserting $y_{n+1}=\rho_{n}^{-1}\left(y_{n}\right)$, one can see (25) holds iff $y_{n} \geq \gamma_{n}$.

${ }^{12}$ As above, we are asserting here that $x$ cannot go from $A_{N+1}$ to $A_{N+2}$ when $A_{n}=0$ for all $n>N+1$. The proof is a special case of a no-bubble result given below.
} 


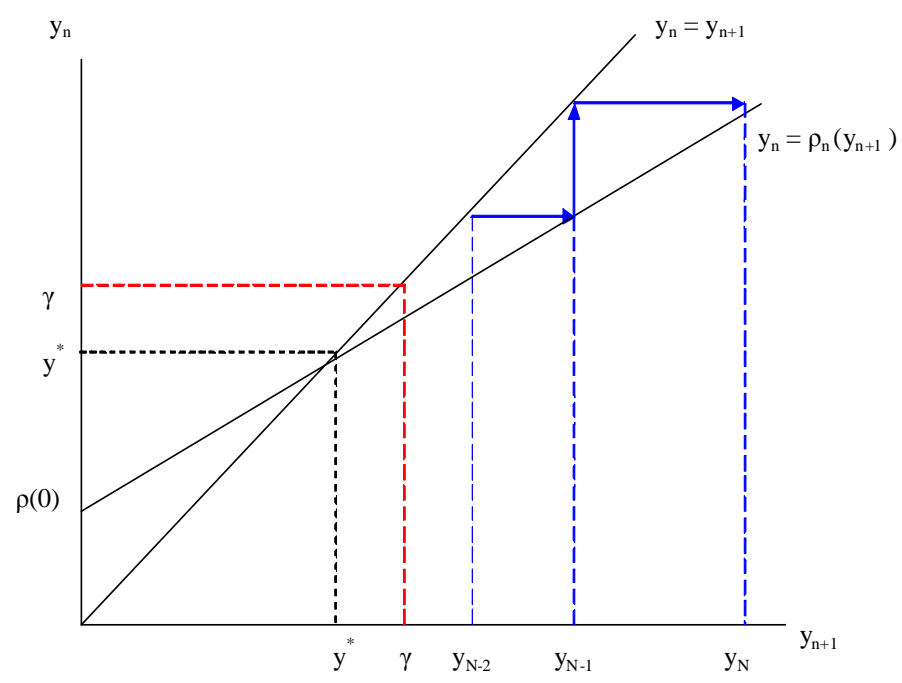

Figure 4: Path of $y_{n}$

going backwards in time, this would involve starting arbitrarily close to $y^{*}<\gamma$, and if $y_{n}<\gamma$ the holder of $x$ would rather consume it than search. Consider e.g. starting with $A_{N-2}$ holding $x$. Suppose $A_{N-2}$ searches and trades $x$ to $A_{N-1}$, who then searches and trades with $A_{N}$, who finally searches and trades $x$ to the end user $A_{N+1}$. To see if this is viable, solve for $y_{N-2}=\rho^{2}\left(y_{N}\right)=\rho^{2}[(1-\theta) \gamma+\theta \hat{\gamma}]$ and check

$$
\bar{V}_{N-2}=\frac{\alpha \rho^{2}\left(y_{N}\right)-c}{r+\alpha} \geq \gamma .
$$

If $c$ is not too big, we can support trade with two middlemen between the originator and end user. For any $c>0$ we cannot support trade with an arbitrary number of middlemen, however, since $y_{N-j} \rightarrow y^{*}<\gamma$, so there is a maximum viable chain. However, if $\gamma=c=0$, then $y^{*}=0$ and there are arbitrarily long chains starting near 0 and ending at $y_{N}$. Even this simple model generates some interesting predictions. To further illustrate, let $T_{n}$ be the random date when $A_{n}$ trades $x$ to $A_{n+1}$. We focus now on two properties of the trading process, one from economics and one from statistics.

First, as is obvious from Figure 4, we point out that $\triangle y$ increases over time: $y_{N}-y_{N-j}>$ $y_{N-j}-y_{N-j-1}$. Thus, as $x$ gets closer to the end user, not only $y$ but the increments in $y$ rise. Second, since the underlying arrival rates are Poisson, as is well known, the interarrival times 


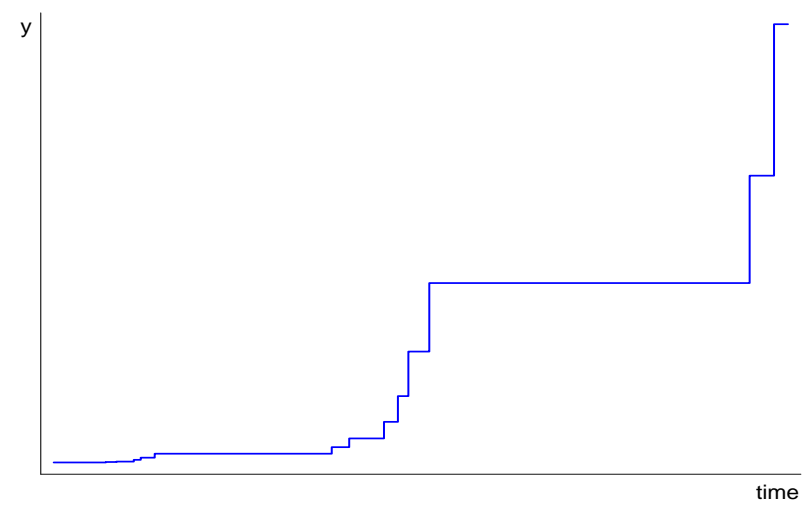

Figure 5: Typical realized path for $y$

$T_{n}-T_{n-1}$ are distributed exponentially. This entails a high probability of short, and a low probability of long, interarrival times. Hence, typical realizations of the process have trades clsutered, with many exchanges occurring in short intervals separated by long intervals of inactivity. This gives the appearance of market frenzies interspersed by lulls, although (since Poisson arrivals are memoryless) there are no frenzies or lulls in any meaningful economic sense. ${ }^{13}$ Figure 5 illustrates these two features: the statistical property that intervals of rapid activity are interspersed by long lulls; and the economic property that $y$ grows at an increasing rate as it approaches the end user, and the ultimate value $y_{N}=(1-\theta) \gamma+\theta \hat{\gamma}$.

\section{Discussion}

Since the Introduction, we have refrained from using the words buyer, seller and price. This is intentional, as we want to raise some issues associated with such usage. First, we contend that in the analog to our model found in much of the search literature, in our notation, $x$ represents a good and $y$ money, and with this interpretation $y$ is the price, the agent who trades $x$ for $y$ is a seller, and the one who trades $y$ for $x$ is a buyer. Noteworthy papers that

\footnotetext{
${ }^{13}$ This is explained in any good text on stochastic processes. As Çinlar $(1975,79-80)$ puts it: "the interarrival times $T_{1}, T_{2}-T_{1}, T_{3}-T_{2}, \ldots$ are independent and identically distributed random variables, with the ... exponential distribution ... Note that this density is monotone decreasing. As a result, an interarrival time is more likely to have a length in $[0, s]$ than in a length in $[t, t+s]$ for any $t$. Thus, a Poisson process has more short intervals than long ones. Therefore, a plot of the time series of arrivals on a line looks, to the naive eye, as if the arrivals occur in clusters." However, the memoryless property actually implies that "knowing that an interarrival time has already lasted $t$ units does not alter the probability of its lasting another $s$ units."
} 
we interpret in this way include, in addition those on middlemen discussed earlier, Diamond (1971,1987), Butters (1977), Burdett-Judd (1983) and Rubinstein-Wolinsky (1985), all of which have an indivisible object corresponding to $x$ called a consumption good (or in some applications a production good like labor), and a divisible object $y$ interpreted as the price (or wage). Of course, although they may think of $y$ as dollars, and very often say so explicitly, these models do not literally have money - what they have is transferrable utility. ${ }^{14}$

Identifying money with (more accurately, confusing money with) transferrable utility is standard fare by even the best economic theorists. Consider Binmore (1992): "Sometimes it is assumed that contracts can be written that specify that some utils are to be transferred from one player to another ... Alert readers will be suspicious about such transfers ... Utils are not real objects and so cannot really be transferred; only physical commodities can actually be exchanged. Transferable utility therefore only makes proper sense in special cases. The leading case is that in which both players are risk-neutral and their von Neumann and Morgenstern utility scales have been chosen so that their utility from a sum of money $x$ is simply $U(x)=x$. Transferring one util from one player to another is then just the same as transferring one dollar." Unfortunately, it ain’t necessarily so - and this is about more than an abhorrence for the dubious, if evidently not discredited, practice of putting money in the utility function.

\footnotetext{
${ }^{14}$ Submitted in evidence, from middlemen papers, consider the following. Rubinstein and Wolinsky (1987, p.582) describe payoffs as the "consumption values (in monetary terms) of a unit." Biglaiser (1993, p.213) starts with "Each buyer is endowed with money." Yavas (1994) describes a standard model of middleman by "The sellers and the middlemen value the good (in monetary terms) at zero, while the buyers value the good at one." Yavas (1992) is more careful, saying "In order to avoid the additional questions associated with having money in the economy, this endowment has not been labeled as money." Johri and Leach (2002) are also careful to say "units of a divisible numeraire good are exchanged for units of an indivisible heterogeneous good," although they have no problem assuming payoffs are linear in the former. Even those less cavalier about money are quick to decide who is the buyer and seller, and what is the price.

Considering search models outside the middleman literature, Butters (1977, p.466) says "A single homogeneous good is being traded for money." Burdett and Judd (1983, pp.955,960) say consumers search "to lower the expected costs of acquiring, a desired commodity, balancing the monetary cost of search against its monetary benefit," and firms want to "make more money." Diamond $(1971,1987)$ does not mention money explicitly, although he does refer, in our notation, to $y$ as the price, and buyers are those with payoff $\gamma-y$ while sellers are those with payoff $y$, in our notation. In many places in their book, Osborne and Rubinstein (1990) decribe models as "A single indivisible good is traded for some quantity of a divisible good ('money')." Gale (1987, p.20) more accurately says "A single, indivisible commodity is traded. Buyers and sellers have transferable utility." One can go on, but we think this makes the point that, with exceptions, most papers suggest that we interpret $x$ as a good, $y$ as a price in money, $A_{n}$ as the seller and $A_{n+1}$ as the buyer.
} 
In serious monetary theory, it is not trivial to transfer dollars across agents, because they tend to run out - no one has an unlimited supply of cash, and for almost all inflation rates (except the Friedman rule) agents carry less than the amount required for unconstrained trade. And, in any case, payoffs are usually not linear in dollars (with some exceptions, e.g., Lagos and Wright 2005). Examples of search-based monetary theory that looks more like the setup in this paper include the models discussed in Shi (1995), Trejos-Wright (1995), Kocherlakota (1998), Wallace (2001) and many other papers. The point we emphasize is that all those models take a diametric position to the above-mentioned applications outside of monetary economics: they assume $y$ is a consumption good and $x$ is money. The most apparent difference is that, under one interpretation, money is divisible and consumption goods are indivisible, while under the other, money is indivisible and goods indivisible. Superficially this favors the first interpretation, where $y$ is money, since divisibility is one of the properties (along with storability, portability and recognizability) commonly associated with money. On reflection, however, we do think this detail should be given much weight. ${ }^{15}$

A better discriminating criterion stems from the functional definitions of money: it is a unit of account, a store of value, and a medium of exchange. The unit of account function - which means that American prices tend to be quoted in dollars, and European prices in euros - seems relatively uninteresting, because for anything of consequence it cannot matter whether we measure prices in dollars or euros any more than whether we measure distance in feet or meters. Moving to the store of value function, it seems clear that in our baseline search model it is actually $x$ and not $y$ that constitutes a store of value: $x$ is a durable good that, when acquired by $A_{n}$ at some date, enables him to enjoy a payoff $y_{n}$ at some future date. The more natural interpretation of $y$ is that it is a perishable good, or a service rather than a good, that is not carried across time but produced for immediate consumption. It seems hard to imagine a perishable good or service serving as money. By contrast $x$, which is kept in inventory, is obviously a storable asset.

\footnotetext{
${ }^{15}$ One reason is that earlier contributions to the search-based monetary literature actually have both $x$ and $y$ indivisible, while more recent ones have them both divisible (see the surveys cited in the Introduction). Another is that, as a matter of historical fact, objects used as money including coins were often less-thanperfectly divisible, with significant economic consequences (e.g., Sargent and Velde 2000).
} 
Moreover, $x$ satisfies the standard definition of a medium of exchange: an object that is accepted in trade not to be consumed or used in production by all who that accepts it, but instead to be traded again later. Now, in the above model $x$ happens to be commodity money, since an end user ultimately does consume it for a direct payoff, as opposed to fiat money which does not generate a direct payoff for anyone. We have more to say about this below; for now, we emphasize that $y$ is not a medium of exchange in the above specification: it is accepted by everyone for its direct payoff, and never to be traded again later. Moreover, it is exactly the classic double-coincidence problem that makes $x$ useful here: when $A_{n}$ wants $y$ from $A_{n+1}$, he has nothing to offer in trade absent asset $x$. Indeed, $x$ can facilitate this exchange even if $A_{n+1}$ does not especially enjoy $x$, as in the case of $\gamma_{n+1}=0$, or, for that matter, $\gamma_{n+1}<0$, since $A_{n+1}$ is only going to trade it again. Based on all this, in terms of calling either $x$ or $y$ money, maybe the monetary search theorists got this one right. ${ }^{16}$

Does it matter? While at some level one might say the issue is purely semantic, as if that were reason not to be interested, we think it actually may matter for how one uses the theory. For instance, it determines who we call the buyer or seller and what we mean by the price. To make this point, we first argue that in nonmonetary exchange - say, when $A$ gives $B$ apples for bananas - it is not meaningful to call either agent a buyer or seller. Of course, one can them whatever one likes, but then the labels buyer and seller convey nothing more than calling them $A$ and $B$. However, when $A$ gives $B$ apples for genuine money, for dollars or euros, everyone should agree that $A$ is the seller and $B$ the buyer (it is perhaps less clear what to call them when $A$ gives $B$ euros for dollars, but that is beside the point). We identify agents who pay money as buyers and ones who receive money as sellers, and claim this corresponds to standard usage. ${ }^{17}$

\footnotetext{
${ }^{16}$ One can also argue $x$ plays much the same role that money plays in non-search monetary models, such as overlapping-generations models (Wallace 1980). Fleshing this out might be interesting.

${ }^{17}$ As evidence, consider the following definitions of the verbs buy and sell: "acquisition of an article, and legal assumption of its ownership, in exchange for money or value" and "to transfer ownership of a property in exchange for money or value" (businessdictionary.com); "to aquire possession, ownership, or rights to the use or services of by payment especially of money" and "to give up (propery) for something of value (as money)" (Meriam Webster); "to acquire the possession of, or the right to, by paying or promising to pay an equivalent, esp. in money" and "to transfer (goods) to or render (services) for another in exchange for money" (Dictionary.com); or "to get something by paying money for it" and "to give something to someone else in return for money" (Cambridge Dictionaries Online).
} 
Again, one can label objects anything one likes, and be on firm ground logically, if not aesthetically. But would anyone want to reverse the labels in, say, the Mortensen-Pissarides (1994) labor-market model, taking the agents we usually think of as workers and calling them firms, and vice versa? One could prove the same theorems, but it would make a difference when considering applied questions (e.g., should we tax/subsidize search by workers or by firms?). Using the interpretation in the previous middlemen literature, where $y$ is money and $x$ is a good, when $A_{n}$ and $A_{n+1}$ trade the former is the seller and the latter is the buyer. Using the interpretation in the monetary literature mentioned above, where $x$ is money and $y$ is a good, $A_{n}$ is the buyer and $A_{n+1}$ is the seller. If one agrees that it makes a substantive difference who we call workers and firms in the labor market, it can similarly make a difference who we call buyers and sellers in goods markets (e.g., for substantive questions, like should we tax/subsidize shoppers or retailers?).

Moreover, the two interpretations give opposite predictions for price behavior. If we normalize the size of the indivisible $x$ to 1 , without loss of generality, under the interpretation that $y$ is money and $x$ is a good, the price is obviously $y$. But if $y$ is the good and $x$ is money then $1 / y$ is the price, since now a normalized unit of money buys $y$ units of the good. To see how this matters, look back at Figure 5. Using the first interpretation, theory predicts prices are rising over time, as more and more money $y$ is required to buy the same amount of consumption good $x$ as it moves closer to the end user. Using the second interpretation, prices are falling, as over time more and more consumption $y$ can be had for the same amount of money $x$. For empirical work, at least, one has to make a choice. We do not intend to ordain one impeccable or irreproachable interpretation, since this may well depend on the issues at hand. We do think it is relevant to broach the issue.

We also find it intriguing that, from a legal standpoint, it often makes a vital difference who we construe as buyer and seller. It is not uncommon to have laws or conventions that allow buyers to return goods and demand a refund, or at least store credit, within a certain period of time, with no questions asked - the principle of caveat emptor notwithstanding. ${ }^{18}$

\footnotetext{
18 "The two basic types of warranties are express warranties and implied warranties. An express warranty is any representation or affirmation about the goods made by the seller's words or conduct. ... Implied
} 
It is harder to imagine similar laws or conventions applying to sellers. With rare exceptions, such as bad checks or counterfeit currency, accepting monetary payment entails finality suggesting a more rigorous principle of caveat venditor. Also, in law, "There is a 'bias' in favour of buyers. Buyers are not obligated to disclose what they know about the value of a seller's property, but sellers are under a qualified obligation to disclose material facts about their own property." (Ramsay 2006). Beyond legal systems narrowly construed, is also true that private trading platforms, like ebay, have rules and regulations that treat buyers and sellers differently (Beal 2009).

We also cannot help but comment on the asymmetric treatment of buyers and sellers in illegal markets. It is commonly understood that with drugs and prostitution, the one who receives the money is usually treated much more harshly than the one who pays (which raises a question about trading drugs directly for sex, but like trading dollars for euros, this is beside the point). Indeed, with drugs, it is so much more common to target sellers than buyers that targeting the latter is referred to as a "reverse sting" operation. With prostitution, historically buyers have almost always been treated much more leniently than sellers. ${ }^{19}$ Similarly, where gambling and drinking are illegal, sellers are typically deemed the bigger villains. The same can be said for the markets for illegal guns, fireworks and so on. Although we are less sure about this case, it may also be true for stolen merchandise - and note that a fence is not much different from a middleman in our model. Intermediaries in general are often considered less than honorable, if not outright heinous, since they do not themselves produce anything but simply profit from others, as evidenced by our epigraph referring to "bloodsucking bastards" and by other timeless condemnations of moneylenders

warranties are warranties that are imposed on sellers by law. A warranty of merchantability is implied in every sales contract. This warranty is a promise that the goods pass without objection in the trade, are adequately packaged, conform to all promises or affirmations of fact on the container, and are fit for the ordinary purposes for which such goods are used. The implied warranty of merchantability also includes a promise that multiple goods will be of even kind and quality." From "Sales Law - Warranties" at http://law.jrank.org/pages/9989/Sales-Law-Warranties.html.

${ }^{19}$ See the "The Staight Dope" at http://www.straightdope.com/columns/read/2774/prostitution. Of course, some argue that this is merely another manifestation of male dominance: "As long as society remains male dominated, women selling sex will be in a more vulnerable position than men buying sex." See "The swedish approach to prostitution" at http://www.sos-sexisme.org/English/swedish.htm. This suggest an obvious empirical test by looking at male prostitutes - if one were willing to swallow some rather dubious ceterus paribus assumptions. 
and the like. This is, of course, mainly out of ignorance of the idea that getting goods from $A$ to $B$ is a productive activity.

In any case, for what it's worth, we find it is the norm to deem sellers - those who receive money in exchange for goods - worse in legal and moral senses than buyers - those who receive goods in exchange for money. Of course, there are exceptions, say in the case of in child prostitution, but this can be explained by saying that the distinction between adults and minors takes precedence over the distinction between buyers and sellers without denying the existence of the latter. Another exception might be when a student - or, perish the thought, a professor - gives someone money to write a paper for them. ${ }^{20}$

Returning to theory, let us reconsider Figure 1. The traditional middleman approach interprets $x$ as a consumption good being passed from originator to end user along a chain of intermediaries. At each link in the chain $x$ trades for $y_{n}$ units of money - or, better, for $y_{n}$ transferable utils - or, better still, for some amount of a different consumption good that is produced at cost $y_{n}$ by $A_{n+1}$ and consumed for utility $y_{n}$ by $A_{n}$. We have no problem with linear utility, our quibble is more about agents getting direct utility from money, or if it is interpreted as indirect utility, it is mostly about cavalierly asserting that the value function is linear in dollars. These issues aside, we think our framework provides a useful model of intermediation chains, where one good $x$ trades for another good $y$, or even a sequence of different goods $\left\{y_{n}\right\}$, since it is easy to imagine $A_{n}$ altering or improving $x$ in some way before he flips it to $A_{n+1}$. But it is also a coherent model of agents trading an asset $x$ in exchange for goods produced at cost $y_{n}$ by $A_{n+1}$ and consumed for utility $y_{n}$ by $A_{n}$.

\footnotetext{
${ }^{20}$ Our objective here is mainly to point out some asymmetries between buyers and sellers, and not to explain them. However, one rationale for focusing enforcement efforts on drug and gun dealers, rather than buyers, is that there are barriers to entry at least at the high end, so that it will be difficult for newcomers to replace those who are incarcerated (Koper and Reuter 1995). However, the reverse argument can be made at the lower end, where one dealer removed from a streetcorner is very quickly replaced by another. Other arguments one hears include the view that those who profit most from illegal activity should be at highest risk of being punished, as should those that serve as role models for entrants due to their financial success. Another is the principle that we tend to judge ethically actions that put others at risk more harshly than actions by people that put themselves at risk, but while this might ring true for drugs it seems difficult to make the case for prostitution. The same might be said for the position that if $B$ is weak and $A$ exploits that weakness, $A$ should be judged more harshly. There is also the idea that for many markets, legal or illegal, sellers have a lot more transactions than buyers, making it more cost effective to go after the former. We must leave these interesting issues for future study.
} 
Also notice that if we use modulo $N$ arithmetic, this chain becomes a circle, where $A_{1}$ consumes the output of $A_{2}$ who consumes the output ... of $A_{N}$ who consumes the output of $A_{1}$. This looks much like the environment used to study money in Kiyotaki and Wright (1989), or at least the generalization in Aiyagari and Wallace (1991). Given that, one wonders, can the model could support equilibria where $x$ is never consumed, or where it has zero consumption value?

\section{Bubbles}

We now consider the notion of bubbles. ${ }^{21}$ In the analysis so far, we could get chains of trade, and with $c_{n}$ small these chains can be quite long, but equilibrium is tied down by the fact that there is a determinate end user who consumes $x$. Now consider the possibility that no one consumes $x$ - it gets traded forever. The indifference condition and best response for $y_{n}$ to $y_{n+1}$ are again given by (23) and (24). As in the analysis of the quasi-stationary environment, we assume here that $\alpha_{n}=\alpha, c_{n}=c$ and $\theta_{n}=\theta$ for all $n$, but now we also assume $\gamma_{n}=\gamma$ for all $n$. In this stationary environment, the best response function becomes

$$
y_{n}=(1-\theta) \gamma+\theta \frac{\alpha y_{n+1}-c}{r+\alpha}=\rho\left(y_{n+1}\right),
$$

as shown in Figure 6. The viability condition for $A_{n}$ to search is $\gamma \leq\left(\alpha y_{n+1}-c\right) /(r+\alpha)$. Compared to the quasi-stationary model with a manifest end user $A_{N+1}$, we no longer have a terminal condition $y_{n}=\theta \gamma+(1-\theta) \hat{\gamma}$.

Since $y_{n}=\rho\left(y_{n+1}\right)$ implies $\partial y_{n+1} / \partial y_{n}=(r+\alpha) / \alpha \theta$, it is clear that there is only one solution to the difference equation that remains nonnegative and bounded: $y_{n}=y^{*}$ for all $n$. Any path that starts at $y>y^{*}$ looks like a bubble: agent $A_{n}$ is willing to search for $A_{n+1}$ because he correctly expects a high $y_{n}, A_{n+1}$ is willing to give a high $y_{n}$ because he expects an even higher $y_{n+1}$, and so on. But clearly such explosive bubbles are not consistent with equilibria as long as we make the standard assumption that there is some upper bound $\bar{y}$ (e.g., $\bar{y}$ could be the total output of known universe). One cannot rationally

\footnotetext{
${ }^{21}$ We will define what we mean by a bubble very soon. The literature on this topic is too big to go into; recent papers by Farhi and Tirole (2010) and Rocheteau and Wright (2010) give extensive references.
} 
believe that $y_{n}$ will grow beyond $\bar{y}$, and hence this bubble-like path for $y_{n}$ cannot be an equilibrium. The only equilibrium is, therefore, $y_{n}=y^{*}$ for all $n$, and since $\gamma>y^{*}$, we have $\bar{V}_{n}=\left(\alpha y^{*}-c\right) /(r+\alpha)<\gamma$. Search is not viable, which seems natural, since there are no gains to trade let alone gains to search when all agents get a common payoff from $x$.

If $A_{n}$ tried to trade $x$ to $A_{n+1}$, off the equilibrium path, he could get exactly $y_{n}=\gamma$ for it (he couldn't get more and he wouldn't take less). We call $y_{n}=\gamma$ the fundamental value of $x$ since this is exactly what it is worth in terms of intrinsic properties. Sometimes people say that whenever $y_{n} \neq \gamma$ there is a bubble, although that does not seem right when agents are bargaining and generally share the surplus. Hence we say there is a bubble when the surplus exceeds

Using the traditional middleman interpretation of $y_{n}$ as the price, $y_{n}>y^{*}$ means the bubble price is above the fundamental value of $x$; using the monetary economics interpretation of $x$ as money and $1 / y_{n}$ as the price, the same inequality means the price is below the fundamental value. What we have shown is that, for this specification, as in most models, bubbles are not possible. ${ }^{22}$ In the quasi-stationary environment analyzed above, paths like the one shown in Figure 5 may resemble bubbles - i.e., $y_{n}$ increases by larger and large increments with each trade - but we do not think of it as a particularly remarkable case, since $\left\{y_{n}\right\}$ is clearly pinned down by fundamentals. We are after bigger game.

To this end, consider making the utility of $y$ more general, say $U(y)$, with $U(0)=0$, $U^{\prime}>0$ and $U^{\prime \prime}<0$. We can keep the cost of producing $y$ equal to $y$ without loss of generality (by a choice of units). Let $y_{\gamma}=U^{-1}(\gamma)$ be the cost of covering $A_{n}$ 's outside option $\gamma$. Then the bargaining indifference condition is

$$
\frac{\alpha_{n+1} U\left(y_{n+1}\right)-c_{n+1}}{r+\alpha_{n+1}}-y_{n}=\left(1-\theta_{n}\right)\left[y_{\gamma}+\frac{\alpha_{n+1} U\left(y_{n+1}\right)-c_{n+1}}{r+\alpha_{n+1}}\right],
$$

which gives the best response condition

$$
y_{n}=\left(1-\theta_{n}\right) y_{\gamma}+\theta_{n} \frac{\alpha_{n+1} U\left(y_{n+1}\right)-c_{n+1}}{r+\alpha_{n+1}}=\rho_{n}\left(y_{n+1}\right) .
$$

\footnotetext{
${ }^{22}$ This is the no-bubble result that confirms our ealier assertions that if $A_{N+1}$ gets $x$ he will consume it in the quasi-stationary model. Also, note that in many models we cannot have prices below fundamental values, as this would violate no-arbitrage. Here arbitrage is limited by the thinness of the market - i.e., search and bargaining.
} 


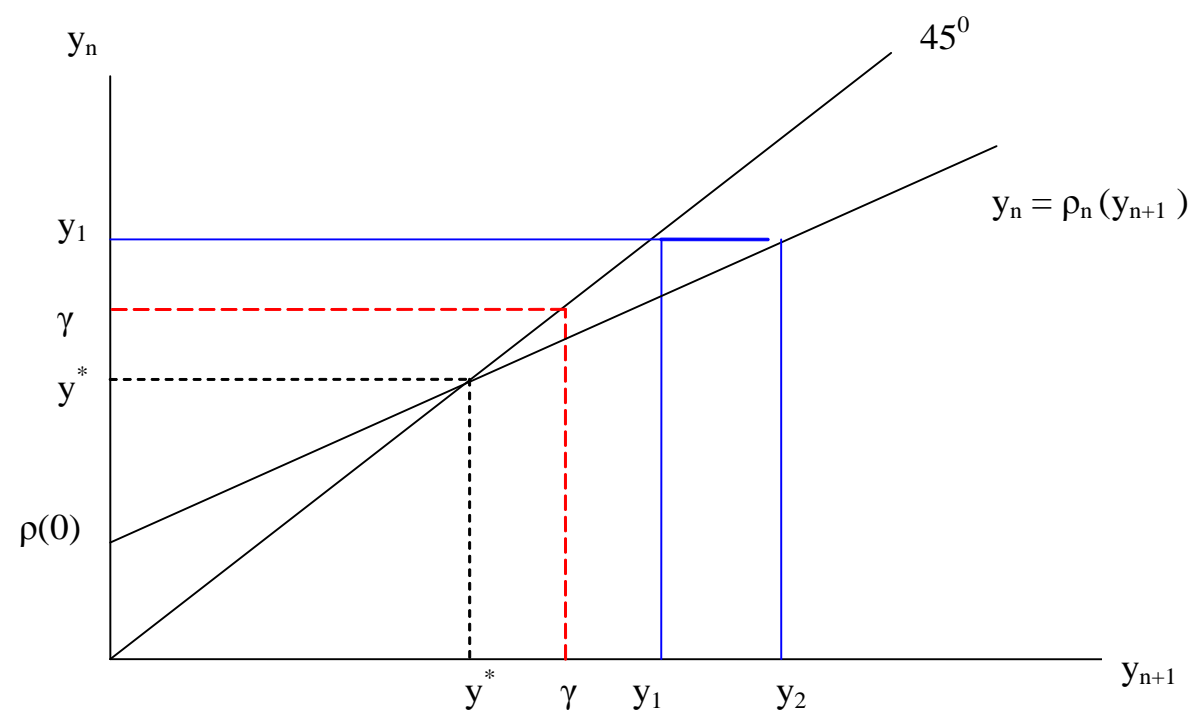

Figure 6: Best response in stationary environment

In a stationary environment,

$$
y_{n}=(1-\theta) y_{\gamma}+\theta \frac{\alpha U\left(y_{n+1}\right)-c}{r+\alpha}=\rho\left(y_{n+1}\right) \text {. }
$$

Figure 7 shows a case where $y^{*}>y_{\gamma}$, or equivalently, $U\left(y^{*}\right)>\gamma$, which we could not get in the linear case $U(y)=y$. Since $U\left(y^{*}\right)>\gamma$ is necessary, but not sufficient, for satisfying the search viability condition $\gamma \leq\left[r U\left(y^{*}\right)-c\right] /(r+\alpha)$, we now at least have a chance, which we did not have with $U(y)=y$. We will show below that the search viability condition holds as long as $\gamma$ is not too big. Also, as drawn, the Figure shows the existence of a unique positive solution to $y^{*}=\rho\left(y^{*}\right)$, which is true iff $0<\rho(0)=(1-\theta) y_{\gamma}-\theta c /(r+\alpha)$. Given $\gamma>0$, this obviously holds if $c$ or $\theta$ is small, or if $\alpha$ is big.

Consider an example with $U(y)=\sqrt{y}$, which means $y_{\gamma}=\gamma^{2}$. Setting $c=0$, for now, for simplicity, we have

$$
\rho(y)=(1-\theta) \gamma^{2}+\frac{\theta \alpha}{r+\alpha} \sqrt{y}
$$

To find a steady state, rewrite $y=\rho(y)$ in terms of $U=\sqrt{y}$ :

$$
U^{2}-\frac{\theta \alpha}{r+\alpha} U-(1-\theta) \gamma^{2}=0
$$




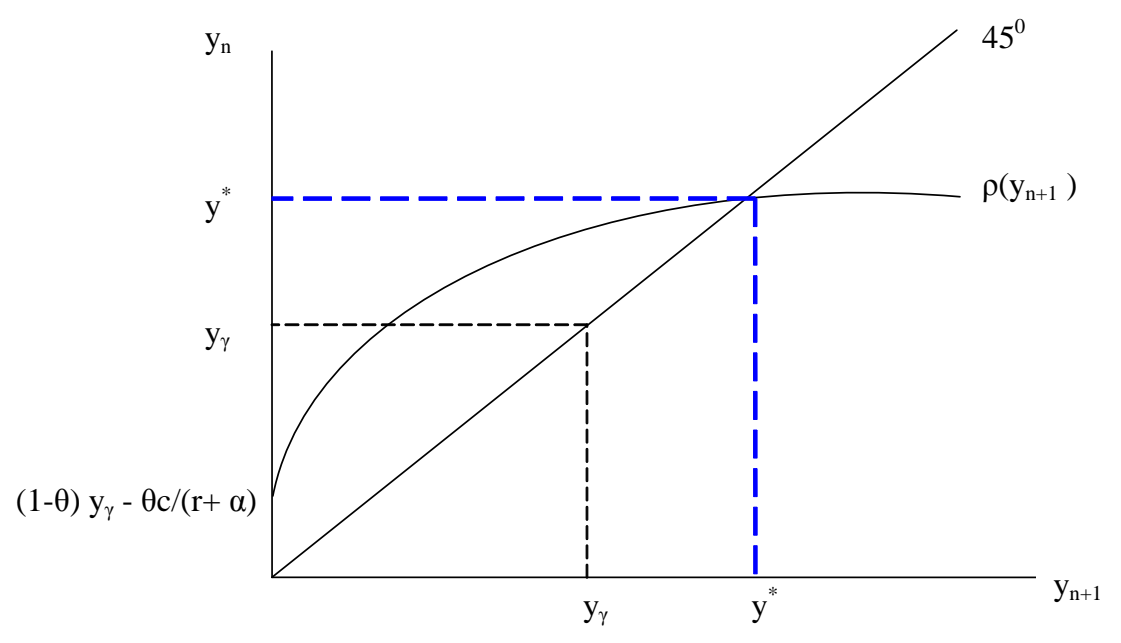

Figure 7: Best response with nonlinear $U(y)$

This is a quadratic in $U$, and the correct (i.e., positive) solution is the higher root

$$
U=\frac{1}{2}\left\{\frac{\theta \alpha}{r+\alpha}+\sqrt{\left(\frac{\theta \alpha}{r+\alpha}\right)^{2}+4(1-\theta) \gamma^{2}}\right\}
$$

The search viability condition $\gamma \leq \frac{\alpha}{r+\alpha} U$ then becomes

$$
2 \gamma \frac{r+\alpha}{\alpha}-\frac{\theta \alpha}{r+\alpha} \leq \sqrt{\left(\frac{\theta \alpha}{r+\alpha}\right)^{2}+4(1-\theta) \gamma^{2}} .
$$

Squaring and simplifying, this reduces to

$$
\gamma \leq \frac{\theta \alpha^{2}}{r^{2}+2 r \alpha+\theta \alpha^{2}} \equiv \bar{\gamma}
$$

Since $\bar{\gamma}>0$, search is viable for some $\gamma>0 .{ }^{23}$

Summarizing, we have shown for this example, with $\gamma<\bar{\gamma}$ and $c=0$, there is an equilibrium such that, for all $n, A_{n}$ searches and trades $x$ to $A_{n+1}$ for $y_{n}=y^{*}$. Appealing to continuity, similar results hold with $c>0$, as long as $c$ is not too big. In this equilibrium

\footnotetext{
${ }^{23}$ Without the assumption $c=0$, one can show search is viable iff $Q(\gamma) \geq 0$, where $Q(\cdot)$ is the quadratic

$$
Q(\gamma)=-\gamma^{2}\left[r^{2}+2 r \alpha+\alpha^{2} \theta\right]+\gamma\left[\alpha^{2} \theta-2(r+\alpha) c\right]-c^{2} .
$$

Hence, $\exists \bar{c}>0$ such that $c<\bar{c}$ implies search is viable for $\gamma \in\left[\gamma_{1}, \gamma_{2}\right]$, with $0<\gamma_{1}<\gamma_{2}$; and for $c>\bar{c}$ search is not viable for any $\gamma \geq 0$. As $c \rightarrow 0,\left[\gamma_{1}, \gamma_{2}\right] \rightarrow[0, \bar{\gamma}]$ consistent with (27).
} 
no one ever consumes $x$ - it is an asset that circulates forever as a medium of exchange. For search to be viable we require $\left[\alpha U\left(y^{*}\right)-c\right] /(r+\alpha) \geq \gamma$, and a fortiori $y^{*}>y_{\gamma}$. This says that the amount of $y$ required to acquire $x$ is above the fundamental value, $y^{*}>y_{\gamma}$. This is a genuine bubble. This may be surprising to some, although maybe not to those well versed in monetary theory, where it is understood that objects can be valued for their liquidity over and above their value as consumption goods, the way, say, cigarettes were valued in historical examples where they served not only consumption goods but also media of exchange and stores of value. ${ }^{24}$

So far we have constructed an equilibrium with a stationary bubble, $y_{n}=y^{*}>y_{\gamma}$ for all $n$. Can we have nonstationary bubbles? When $\rho(0)>0$, it is clear from Figure 7 that the answer is no. With $\rho(0)>0$, all paths except $y_{n}=y^{*}$ for all $n$ either lead to $y_{n}<0$, or explode so that eventually $y_{n}>\bar{y}$. But suppose $\rho(0)<0$, as shown in Figure 8, which occurs when $c>y_{\gamma}(r+\alpha)(1-\theta) / \theta$. As long as $c$ is not too big, there are multiple steady states, $y_{1}^{*}$ and $y_{2}^{*}$. As in the Figure, suppose $\alpha\left[U\left(y_{1}^{*}\right)-c\right] /(r+\alpha)>\gamma$, so that near $y_{1}^{*}$, search is viable. Then, as the Figure shows, there are nonconstant paths for $y_{n}$ satisfying all the equilibrium conditions, even though fundamentals are time invariant. From the left, $y_{n}$ rises over time, in progressively smaller increments, until settling at $y_{1}^{*}$; and from the right, $y_{n}$ falls in progressively smaller increments, again settling at $y_{1}^{*}$. In either case, whether we would say the price is rising or falling depends on whether we takes $x$ or $y$ to be money.

In any case, we have nonstationary bubbles. Some of these equilibria might look funny because agents are "buying high and selling low" - for instance, starting to the right of $y_{1}^{*}$, agent $A_{n+1}$ gives up $y_{n}$ to get $x$, and later receives only $y_{n+1}<y_{n}$ in return. This is

\footnotetext{
${ }^{24}$ A classic reference is Radford's (1945, 190-191) description of a POW camp: "Between individuals there was active trading in all consumer goods and in some services. Most trading was for food against cigarettes or other food stuffs, but cigarettes rose from the status of a normal commodity to that of currency. ... With this development everyone, including nonsmokers, was willing to sell for cigarettes, using them to buy at another time and place. Cigarettes became the normal currency." Similarly, Friedman (1992, 12-12) reports: "After World War II [in Germany] the Allied occupational authorities exercised sufficiently rigid control over monetary matters, in the course of trying to enforce price and wage controls, that it was difficult to use foreign currency. Nonetheless, the pressure for a substitute currency was so great that cigarettes and cognac emerged as substitute currencies and attained an economic value far in excess of their value purely as goods to be consumed. ... Foreigners often expressed surprise that Germans were so addicted to American cigarettes that they would pay a fantastic price for them. The usual reply was 'Those aren't for smoking; they're for trading'." That is exactly what is going on here.
} 


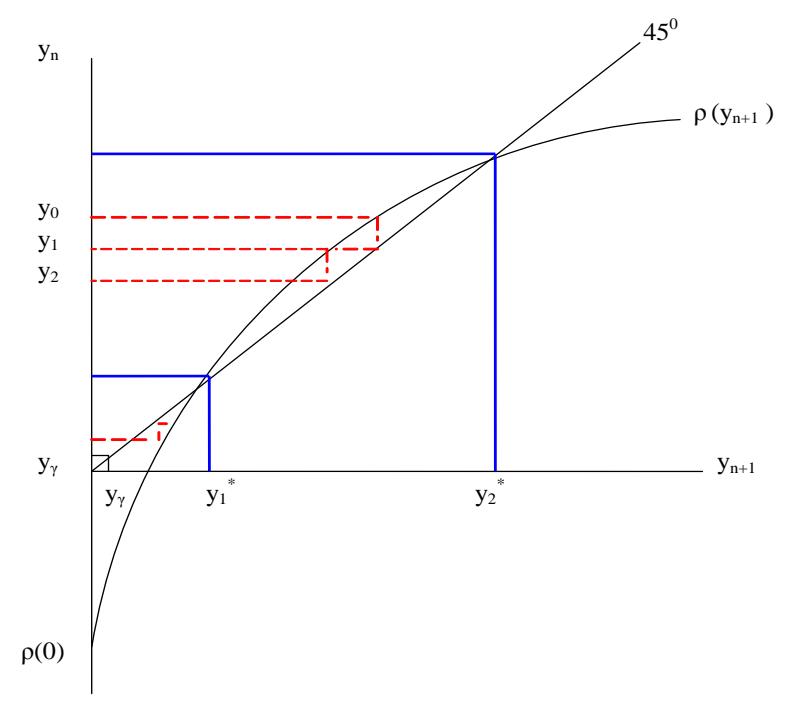

Figure 8: $U(y)$ nonlinear and $c>0$

ostensibly a funny strategy for a middleman, even without accounting for his time and search costs. Yet it is obviously an equilibrium strategy because, although he gives up $y_{n}$ and only receives $y_{n+1}<y_{n}$, the payoff from $y_{n+1}$ is $U\left(y_{n+1}\right)>y_{n}$. Indeed, even the ex ante payoff when $x$ is acquired, taking into account time and search costs, exceeds the cost of acquiring it, or he wouldn't do it. For this we need nonlinear utility.

To close this part of the discussion we want to say more about bargaining. First. it is not necessary to use our particular extensive form to generate interesting dynamics. Suppose one instead uses generalized Nash:

$$
y_{n}=\arg \max _{y}[U(y)-\gamma]^{\theta}\left(\bar{V}_{n+1}-y\right)^{1-\theta}
$$

The FOC is $\theta\left(\bar{V}_{n+1}-y_{n}\right) U^{\prime}(y)=(1-\theta)\left[U\left(y_{n}\right)-\gamma\right]$, which has a unique solution that does not depend on $n$ for any given $\bar{V}_{n+1}$, say $y_{n}=\hat{y}\left(\bar{V}_{n+1}\right)$. Inserting $\bar{V}_{n+1}$ we get a dynamical system analogues to $(26)$ :

$$
y_{n}=\hat{y}\left[\frac{\alpha U\left(y_{n+1}\right)-c}{r+\alpha}\right]=\hat{\rho}\left(y_{n+1}\right) .
$$

This has qualitatively similar properties to the system $y_{n}=\rho\left(y_{n+1}\right)$ derived from our game. The same is true for Kalai's proportional solution, which satisfies

$$
\theta\left(\bar{V}_{n+1}-y\right)=(1-\theta)[U(y)-\gamma]
$$


defining $y_{n}=\tilde{y}\left(\bar{V}_{n+1}\right)$ and $y_{n}=\tilde{\rho}\left(y_{n+1}\right)$.

The three bargaining solutions imply different values of $y_{n}$ but all generate dynamical systems that behave similarly, and all can generate multiple stationary equilibria as well as paths where $y_{n}$ varies with $n$. We like our game because it has explicit strategic foundations. ${ }^{25}$ This is often said to also be a desirable property of Nash bargaining: write down a standard strategic model with randomly alternating counteroffers, take the limit as the time between counteroffers goes to 0 , and out pops the Nash solution, at least in stationary bargaining situations (Binmore 1987; Binmore, Rubinstein and Wolinsky 1986). As demonstrated in Coles and Wright (1998) and Coles and Muthoo (2003), however, this breaks down in nonstationary situations unless one makes additional assumptions, like imposing linear utility or giving one agent all the bargaining power. In general, in a nonstationary bargaining situation, when one writes down the same strategic model, and takes the limit, one gets a differential equation for the terms of trade that equals Nash in steady state but not out of steady state, unless we make special assumptions like (in our notation) $U(y)=y$ or $\theta=1$.

Further, the above-mentioned papers show that the set of dynamic equilibria can be qualitatively different when one uses the correct limit of the game rather than sticking in the Nash solution out of steady state. Further still, the papers show that sticking the Nash solution into the model out of steady state is equivalent to inserting the equilibrium outcome of the alternating-offer game under the assumption that agents have myopic expectations they believe continuation values will not change over time even though in equilibrium they do change over time. To the extent that one wants strategic foundations for bargaining , and wants to analyze dynamic models out of steady state, and wants to use nonlinear utility, there are issues with Nash solution. Less is known about the strategic foundations of proportional bargaining. Of course, we saw earlier that when utility is linear, our game is equivalent to proportional or Nash bargaining. We now compare the three bargaining

\footnotetext{
${ }^{25}$ Nash himself argued that it was important to write down explicit environments where his bargaining solution would arise as an equilibrium, an endeavor now referred to as the Nash program (e.g., Osborne and Rubinstein 1990, chapter 4).
} 
solutions in steady state for the nonlinear $U(y)=\sqrt{y}$ (because we are looking at steady state, the Nash solution does follow as the limit of a strategic bargaining game, just not our strategic bargaining game).

One can solve the example with our strategic bargaining solution, the Nash solution, and the proportional solution. In Appendix B we show that for each case there are upper bounds for $\gamma$ that make search viable, and when $c=0$ these are given by

$$
\begin{aligned}
\bar{\gamma}_{s} & =\frac{\theta \alpha^{2}}{r^{2}+2 r \alpha+\theta \alpha^{2}} \\
\bar{\gamma}_{n} & =\frac{\theta \alpha^{2}}{r^{2}(2-\theta)+2 r \alpha+\theta \alpha^{2}} \\
\bar{\gamma}_{p} & =\frac{\alpha[\theta \alpha-r(1-\theta)]}{\theta(r+\alpha)^{2}},
\end{aligned}
$$

where the subscripts $s, n$, and $p$ signify strategic, Nash and proportional bargaining, and we assume $\theta \alpha>r(1-\theta)$. We can show $\bar{\gamma}_{n} \leq \bar{\gamma}_{s}<1$ and $\bar{\gamma}_{p}<1$, but the relationship between $\bar{\gamma}_{p}$ and the other two is unclear. When $\theta=1$, all are equal to $\bar{\gamma}=\alpha^{2} /(r+\alpha)^{2}$. If we let $r \rightarrow 0$, then all are equal to 1 independent of $\theta$. Also, in this case steady state equilibrium payoffs are

$$
\begin{aligned}
U_{s} & =\frac{1}{2}\left[\theta+\sqrt{\theta^{2}+4(1-\theta) \gamma^{2}}\right] \\
U_{n} & =\frac{1}{2-\theta}[2 \gamma(1-\theta)+\theta] \\
U_{p} & =\frac{1}{2 \theta}[2 \theta-1+\sqrt{1-4 \theta(1-\gamma)(1-\theta)}]
\end{aligned}
$$

We can show $y_{n}^{*}<y_{s}^{*}<1$, and $y_{n}^{*}=y_{s}^{*}=1$ when $\theta=1$. The relationship with $y_{p}^{*}$ is less clear. The following graphs show $y$ as a function of $\theta$ for two examples, with different values of $\gamma$, illustrating how one cannot compare the solutions in general. We conclude that, with nonlinear utility, even when we look at steady states, these different bargaining solutions generally give different answers. Again, we like our solution because it has a simple strategic foundation, in and out of steady state. We wanted to look at economies out of steady state because we are interested in nonstationary bubbles, and we needed to look at nonlinear utility because this is necessary to get such an outcome. However, if one cares less about strategic foundations, one can use other bargaining solutions are get similar results. The 
model of intermediated trade, or, from a different perspective, the model of an indivisible asset being used as a medium of exchange, works fine with any bargaining solution.

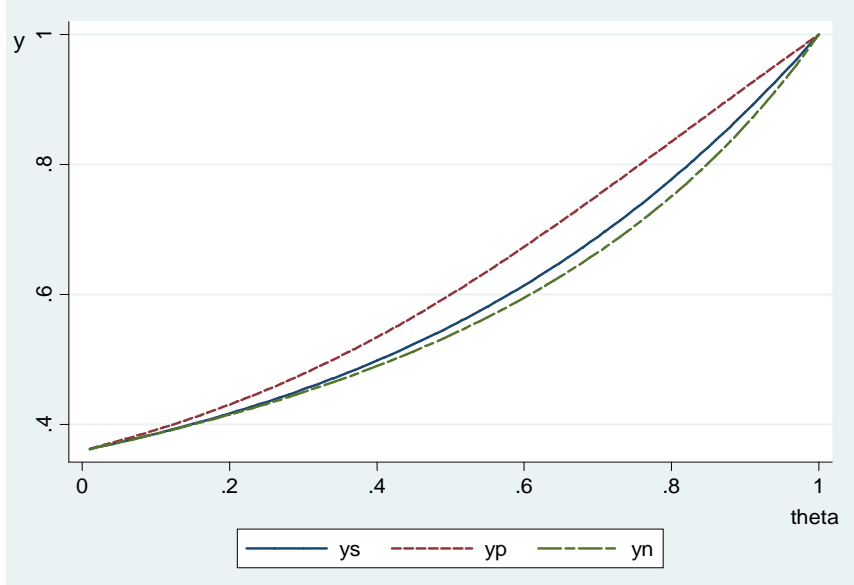

Model comparison when $\gamma=0.6$

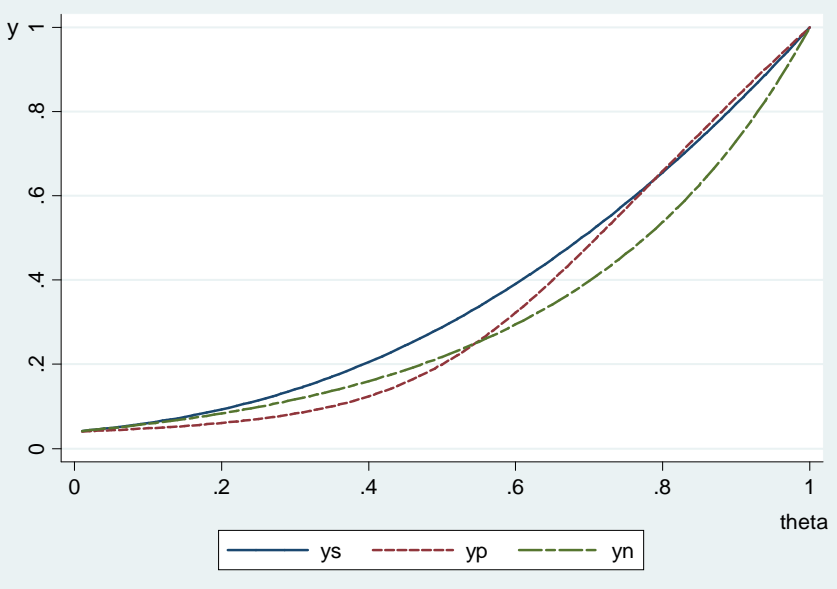

Model comparison when $\gamma=0.2$

\section{Conclusion}

We conclude as we began, by saying that we are interested in trade that may be intermediated by middlemen. We showed how to get middlemen, and sometimes long chains of middlemen, even infinite chains, with no end user in sight, that look like bubbles. This arose naturally from our discussion of buyers versus sellers and goods versus money that itself arose from our reading of the middleman and money literatures. There has been much progress on these topics, much of it based on search theory and related techniques (the economics of information), which is not surprising given money and middlemen are both institutions that unquestionably exist to ameliorate frictions in the process of exchange. What is surprising is that there is not much connection between the literatures, although there are a few papers that discuss some of the issues, including $\mathrm{Li}$ (1999). We think we have something to contribute by highlighting the similarities and differences between existing models, and by raising some new issues.

One new issue on which we focus is the phenomenon of intermediation chains, where $A$ 
sells to $B$ who sells to $C$ and so on. A related issue concerns fleshing out ideas about bargaining with bargainers, leading to further insights on the ubiquity of holdup problems. We also presented a comparison of various bargaining solutions. We think the strategic bargaining solution on which we mainly focus is an attractive one for search models, especially those with nonlinear utility and nonstationary equilibria, as in monetary theory. Many applications of these ideas are potentially interesting, including applications in financial markets, and perhaps especially in real estate markets, where flipping is a prevalent activity. Additional research might also look into why producers often trade only with large or established wholesalers, stymieing efforts to disintermediate, or, to cut out the middleman. It would also be interesting to try to understand further how buyers and sellers are different and why they are often treated so differently, as they are by the legal system. We leave all of this to future research. 


\section{Appendix A}

Here we give the details behind the results in Section 3. Consider first type 2 equilibrium with $\sigma_{1}=1$ and $\mu=1$. First, compute

$$
\bar{V}_{21}-\bar{V}_{20}=\frac{\sigma_{2} \alpha_{23} y_{23}+\sigma_{1} \alpha_{21} \mu y_{12}-\sigma_{2} c_{2}}{r+\sigma_{2} \alpha_{23}+\sigma_{1} \alpha_{21} \mu} .
$$

Using this, we get

$$
\begin{aligned}
y_{23} & =\frac{\left[r+\sigma_{2} \alpha_{23}+\sigma_{1} \alpha_{21} \mu\left(1-\theta_{12}\right)\right] \theta_{23} \gamma_{3}-\left(1-\theta_{23}\right) \sigma_{2} c_{2}}{r+\sigma_{2} \theta_{23} \alpha_{23}+\sigma_{1} \alpha_{21} \mu\left(1-\theta_{12}\right)} \\
y_{12} & =\frac{\sigma_{2} \theta_{12}\left(\alpha_{23} \theta_{23} \gamma_{3}-c_{2}\right)}{r+\sigma_{2} \theta_{23} \alpha_{23}+\sigma_{1} \alpha_{21} \mu\left(1-\theta_{12}\right)},
\end{aligned}
$$

and hence

$$
\bar{V}_{21}-\bar{V}_{20}=\frac{\sigma_{2}\left(\alpha_{23} \theta_{23} \gamma_{3}-c_{2}\right)}{r+\sigma_{2} \theta_{23} \alpha_{23}+\sigma_{1} \alpha_{21} \mu\left(1-\theta_{12}\right)} .
$$

Thus, $\mu=1$ iff $\alpha_{23} \theta_{23} \gamma_{3} \geq c_{2}$. Now substituting $\alpha_{21}=\pi_{1} \alpha_{12} / \pi_{2}, y_{13}, y_{12}$ and $m$ into (12) and setting $\sigma_{1}=\mu=1$, we see that $\sigma_{1}=1$ iff (20) in the text holds.

Next consider type 1 equilibrium with $\sigma_{1}=1$ and $\mu=0$. First, we check that when $A_{1}$ and $A_{2}$ meet, they do not trade. To determine this we have to determine what would happen if they did trade. Consider the problem when $A_{2}$ with $x$ meets $A_{3}$. The indifference condition with $\bar{V}_{20}=0$ (because $A_{2}$ never again gets $x$ in this equilibrium) implies

$$
\bar{V}_{21}=\frac{\alpha_{23} \theta_{23} \gamma_{3}-c_{2}}{\left(r+\alpha_{23} \theta_{23}\right)} .
$$

The we can back up to when $A_{1}$ and $A_{2}$ meet and solve for $y_{12}$. Now consider the problem between $A_{1}$ and $A_{3}$. Substituting $y_{13}$ into $\bar{V}_{1}$, we have

$$
\bar{V}_{1}=\frac{\alpha_{13} \theta_{13} \gamma_{3}-c_{1}}{r} .
$$

Thus, $\sigma_{1}=1$ iff $\bar{V}_{1} \geq 0$ iff $\alpha_{13} \theta_{13} \gamma_{3} \geq c_{1}$. Then $\mu=0$ iff $\bar{V}_{21} \leq 0$ is given by $\alpha_{23} \theta_{23} \gamma_{3} \leq c_{2}$.

Finally, consider type 0 equilibrium, $\sigma_{1}=0$. The first subcase is $\mu=1$, which holds iff $\alpha_{23} \theta_{23} \gamma_{3} \geq c_{2}$. Then $\sigma_{1}=0$ iff the condition given in the text holds. The other subcase is $\mu=0$, which holds iff $\alpha_{23} \theta_{23} \gamma_{3} \leq c_{2}$. Then $\sigma_{1}=0$ iff $\alpha_{13} \theta_{13} \gamma_{3} \geq c_{1}$. This completes the argument. 


\section{Appendix B}

Here we give some more details concerning the example with $U(y)=\sqrt{y}$. First, we can extend the case of our bargaining solution by relaxing the assumption $c=0$ made in the text. One can show search is viable iff $Q(\gamma) \geq 0$, where $Q(\cdot)$ is the quadratic

$$
Q(\gamma)=-\gamma^{2}\left[r^{2}+2 r \alpha+\alpha^{2} \theta\right]+\gamma\left[\alpha^{2} \theta-2(r+\alpha) c\right]-c^{2} .
$$

Hence, $\exists \bar{c}>0$ such that $c<\bar{c}$ implies search is viable for $\gamma \in\left[\gamma_{1}, \gamma_{2}\right]$, with $0<\gamma_{1}<\gamma_{2}$; and for $c>\bar{c}$ search is not viable for any $\gamma \geq 0$. As $c \rightarrow 0,\left[\gamma_{1}, \gamma_{2}\right] \rightarrow[0, \bar{\gamma}]$ consistent with (27).

Now consider the FOC from generalized Nash bargaining, $\theta y=\theta \bar{V}-(1-\theta)[\sqrt{y}-\gamma] 2 \sqrt{y}$. Substituting $\bar{V}$ and rearranging terms, the steady state $y$ solves

$$
(2-\theta)(r+\alpha) y-[2 \gamma(1-\theta)(r+\alpha)+\alpha \theta] \sqrt{y}+c \theta=0 .
$$

The solution satisfies

$$
\sqrt{y}=\frac{[2 \gamma(1-\theta)(r+\alpha)+\alpha \theta]+\sqrt{[2 \gamma(1-\theta)(r+\alpha)+\alpha \theta]^{2}-4(2-\theta)(r+\alpha) c \theta}}{2(2-\theta)(r+\alpha)}
$$

Inserting $U=\sqrt{y}$ into the viability condition $\gamma \leq(\alpha U-c) /(r+\alpha)$ and simplifying, we have

$$
\gamma^{2}\left[r^{2}(2-\theta)+2 r \alpha+\alpha^{2} \theta\right]+\gamma\left\{[r(2-\theta)+\alpha] 2 c-\alpha^{2} \theta\right\}+(2-\theta) c^{2} \leq 0 .
$$

Again there exists $\bar{c}>0$ such that $c<\bar{c}$ implies search is viable for $\gamma \in\left[\gamma_{1}, \gamma_{2}\right]$, with $0<\gamma_{1}<\gamma_{2}$; and for $c>\bar{c}$ search is not viable for $\gamma \geq 0$.

One can do the same for proportional bargaining. At steady state, we have

$$
\theta y+\frac{[(1-\theta) r+\alpha]}{r+\alpha} \sqrt{y}+\left[\frac{c \theta}{r+\alpha}-\gamma(1-\theta)\right]=0 .
$$

The solution satisfies

$$
\sqrt{y}=\frac{1}{2 \theta}\left\{-[(1-\theta) r+\alpha] /(r+\alpha)+\sqrt{\frac{[(1-\theta) r+\alpha]^{2}}{(r+\alpha)^{2}}-4 \theta[c \theta /(r+\alpha)-\gamma(1-\theta)]}\right\},
$$

and the viability condition is

$$
\gamma^{2}(r+\alpha)^{2} \theta+\gamma\{2 \theta c(r+\alpha)+\alpha[r(1-\theta)-\theta \alpha]\}+c[\theta c+\alpha(1-\theta)] \leq 0 .
$$


Again, search is viable iff $c$ is small.

When $c=0$, the upper bounds for $\gamma$ that allow search are as given in (28). Algebra implies $\bar{\gamma}_{n} \leq \bar{\gamma}_{s}<1$ and $\bar{\gamma}_{p}<1$, while the relationship between $\bar{\gamma}_{p}$ and the other two is ambiguous. When $c=0$ and $r \rightarrow 0$, all $\bar{\gamma}_{n}=\bar{\gamma}_{s}=\bar{\gamma}_{p}=1$ independent of $\theta$, and in equilibrium $U$ is given by (29). 


\section{References}

[1] Aiyagari, S. and N. Wallace. 1991. "Existence of Steady States with Positive Consumption in the Kiyotaki-Wright Model," Review of Economic Studies 58, 901-16.

[2] Beal, V. 2009. "EBay Clarifies Buyer and Seller Protection Obligations," online article at http://www.ecommerce-guide.com/article.php/3818976/EBay-Clarifies-Buyerand-Seller-Protection-Obligations.htm

[3] Biglaiser, G. 1993. "Middlemen as Experts," RAND Journal of Economics 24, 212-223.

[4] Binmore, K. 1987. "Perfect Equilibria in Bargaining Models," in The Economics of Bargaining, ed. K. Binmore and P. Dasgupta, Oxford: Blackwell.

[5] Binmore, K. 1992. Fun and Games: A Text on Game Theory. D.C. Health.

[6] Binmore, K., A. Rubinstein and A. Wolinsky. 1986. "The Nash Bargaining Solution in Economic Modelling," RAND Journal of Economics 17, 176-188.

[7] Burdett, K. and M. Coles 1997. "Marriage and Class" Quarterly Journal of Economics $112,141-68$.

[8] Bose G. and A. Sengupta 2010. "A Dynamic Model of Search and Intermediation," Mimeo.

[9] Burdett, K., and Judd, K. 1983. "Equilibrium Price Dispersion," Econometrica 51, 955-70.

[10] Butters, G. 1977. "Equilibrium Distributions of Sales and Advertising Prices," Review of Economic Studies 44, 465-491.

[11] Camera, G. 2001. "Search, Dealers, and the Terms of Trade," Review of Economic Dynamics 4, 680-694.

[12] Çinlar, E. 1975. Introduction to Stochastic Processes, Prentice-Hall.

[13] Coles, M. and R. Wright. 1998. "A Dynamic Equilibrium Model of Search, Bargaining, and Money," Journal of Economic Theory 78, 32-54. 
[14] Coles, M. and A. Muthoo. 2003. "Bargaining in a non-stationary environment," Journal of Economic Theory 109, 70-89.

[15] Cooke, A. 2000. "New Role for the Middleman," online article at http:// www.isoc.org/inet2000/cdproceedings/7d/7d_3.htm

[16] Diamond, P. 1971. "A Model of Price Adjustment," Journal of Economic Theory 2, 156-168.

[17] Diamond, P. 1987. "Consumer Differences and Prices in a Search Model," Quarterly Journal of Economics 102, 429-436.

[18] Dong, M. 2010. "Inflation And Variety," International Economic Review 51, 401-420.

[19] Duffie, D., N. Gârleanu and L. Pederson. 2005. "Over-the-Counter Markets," Econometrica $73,1815-1847$.

[20] Ellis, M. "Wholesale Products And The Middleman-Chain," online article at http://blog.motoring-loans.co.uk/wholesale-products-and-the-middleman-chain/

[21] Farhi, E. and J. Tirole. 2010. "Bubbly liquidity," Working Paper.

[22] Friedman, M. 1994. Monetary Michief. Mariner Books.

[23] Gale, D. 1987. "Limit theorems for markets with sequential bargaining," Journal of Economic Theory 43, 20-54.

[24] Gehrig, T. 1993. "Intermediation in Search Markets," Journal of Economics and Management Strategy 2, 97-120.

[25] Johri, A. and J. Leach. 2002 "Middlemen and the Allocation of Heterogeneous Goods," International Economic Review 43, 347-361.

[26] Kalai, E. 1977. "Proportional Solutions to Bargaining Situations: Interpersonal Utility Comparisons," Econometrica 45, 1623-30.

[27] Kalai, E., A. Postlewaite and J. Roberts. 1978. "Barriers to trade and disadvantageous middlemen: Nonmonotonicity of the core," Journal of Economic Theory 19, 200-209. 
[28] Kiyotaki, N. and Wright, R. 1989. "On Money as a Medium of Exchange," Journal of Political Economy 97, 927-954.

[29] Kocherlakota, N. 1998. "Money is Memory," Journal of Economic Theory 81, 232-251.

[30] Koper, C. and P. Reuter. 1995. "Suppressing Illegal Gun Markets: Lessons from Drug Enforcement," online article at http://www.publicpolicy.umd.edu/files.php/faculty/ reuter/COOK2.pdf.

[31] Lagos, R., and G. Rocheteau. 2009. Liquidity in Asset Markets With Search Frictions, Econometrica 77, 403-426.

[32] Lagos, R. Rocheteau, G. and Weill, P. 2009. "Crises and Liquidity in Over-the-Counter Markets," Mimeo.

[33] Lagos, R. and Wright, R. 2005. "A Unified Framework for Monetary Theory and Policy Analysis," Journal of Political Economy 113, 463-484.

[34] Lester, B., A. Postlewaite and R. Wright. 2010. "Information, liquidity, asset prices and monetary policy," Mimeo.

[35] Li, Y. 1998. "Middlemen and Private Information," Journal of Monetary Economics 42, 131-159.

[36] Li, Y. 1999. "Money and Middlemen in an Economy with Private Information," Economic Inquiry 37, 1-12.

[37] MacCleod, B. and J. Malcomson. 1993. "Investments, Holdups, and the Form of Market Contracts," American Economic Review 838, 811-837.

[38] Masters, A. 2007. "Middlemen in Search Equilibrium," International Economic Review 48, 343-62.

[39] Masters, A. 2008. "Unpleasant Middlemen," Journal of Economic Behavior and Organization 68, 73-86.

[40] Miao, J. 2006. "A search model of centralized and decentralized trade," Review of Economic Dynamics 9, 68-92. 
[41] Mortensen, D. and R. Wright. 2002. "Competitive Pricing and Efficiency in Search Equilibrium," International Economic Review 43, 1-20

[42] Nash, J. 1950. "The Bargaining Problem," Econometrica 18, 155-162.

[43] Nosal, E. and G. Rocheteau. 2010. Money, Payments, and Liquidity. MIT Press.

[44] Osborne, M. and A. Rubinstein. 1990. Bargaining and Markets. Academic Press.

[45] Radford, R.A. 1945. "The Economic Organization of a P.O.W. Camp," Economica.

[46] Ramsay, M. 2006. "The Buyer/Seller Asymmetry: Corrective Justice and Material NonDisclosure," University of Toronto Law Journal 56, 115-149.

[47] Rubinstein, A. and Wolinsky A. 1985. "Equilibrium in a Market with Sequential Bargaining," Econometrica 53, 1133-1150.

[48] Rocheteau, G. and R. Wright. 2010. "Liquidity and Asset Market Dynamics," Working Paper.

[49] Rust, J. and R. Hall. 2003. "Middlemen versus market makers: A theory of competitive exchange," Journal of Political Economy 111, 353-403.

[50] Rubinstein, A. and Wolinsky A. 1987. "Middlemen," Quarterly Journal of Economics 102, 581-594.

[51] Sargent, T. and F. Velde 2003. The Big Problem of Small Change. Princeton University Press.

[52] Shevichenko, A. 2004. "Middlemen," International Economic Review 45, 1-24.

[53] Shi, S. 1995. "Money and Prices: A Model of Search and Bargaining," Journal of Economic Theory 67, 467-496.

[54] Smith, E. 2004. "Intermediated Search," Economica 71, 619-636.

[55] Stahl, I. 1972. Bargaining Theory. Stockholm Research Institute.

[56] Tse, C. 2009. "The Spatial Origin of Commerce," Mimeo. 
[57] Trejos, A. and Wright, R. 1995. "Search, Bargaining, Money, and Prices," Journal of Political Economy 103, 118-141.

[58] Yavas, A. 1992. "Marketmakers versus Matchmakers," Journal of Financial Intermediation 2, 33-58.

[59] Yavas, A. 1994. "Middlemen in Bilateral Search Markets," Journal of Labor Economics 12, 406-429.

[60] Yavas, A. 1996. "Search and Trading in Intermediated Markets," Journal of Economics and Management Strategy 5, 195-216.

[61] Wallace, N. 1980. "The Overlapping Generations Model of Fiat Money," in Models of Monetary Economies, ed. J. Kareken and N. Wallace, Minneapolis: Federal Reserve Bank of Minneapolis.

[62] Wallace, N. 2001. "Whither Monetary Economics?" International Economic Review 42, 847-869.

[63] Watanabe, M. 2010a. "A model of merchants," Journal of Economic Theory 145, 18651889.

[64] Watanabe, M. 2010b. "Middlemen: A Directed Search Equilibrium Approach," Mimeo.

[65] Weill, P. 2007. "Leaning Against the Wind," Review of Economic Studies 74, 1329-1354.

[66] Williamson, S. and R. Wright. 2010a. "New Monetarist Economics: Methods," Federal Reserve Bank of St. Louis Review.

[67] Williamson, S. and R. Wright. 2010b. "New Monetarist Economics: Models," Forthcoming in Handbook of Monetary Economics. 